\title{
On the collocation between dayside auroral activity and coherent HF radar backscatter
}

\author{
J. Moen ${ }^{1,4}$, H. C. Carlson ${ }^{2}$, S. E. Milan ${ }^{3}$, N. Shumilov ${ }^{1}$, B. Lybekk ${ }^{4}$, P. E. Sandholt ${ }^{4}$, M. Lester ${ }^{3}$ \\ ${ }^{1}$ Arctic Geophysics, University Courses on Svalbard, N-9170 Longyearbyen, Norway \\ 2 Air Force Research Laboratory, AFOSR, 801 Stafford St., Arlington, VA 22203, USA \\ ${ }^{3}$ Department of Physics and Astronomy, University of Leicester, Leicester LE1 7RH, UK \\ ${ }^{4}$ Department of Physics, University of Oslo, PO Box. 1048 Blindern, N-0316 Oslo, Norway
}

Received: 20 December 1999 / Revised: 29 September 2000 / Accepted: 6 October 2000

\begin{abstract}
The 2D morphology of coherent HF radar and optical cusp aurora has been studied for conditions of predominantly southward IMF conditions, which favours low-latitude boundary layer reconnection. Despite the variability in shape of radar cusp Doppler spectra, the spectral width criterion of $\geq 220 \mathrm{~m} \mathrm{~s}^{-1}$ proves to be a robust cusp discriminator. For extended periods of well-developed radar backscatter echoes, the equatorward boundary of the $\geq 220 \mathrm{~m} \mathrm{~s}^{-1}$ spectral width enhancement lines up remarkably well with the equatorward boundary of the optical cusp aurora. The spectral width boundary is however poorly determined during development and fading of radar cusp backscatter. Closer inspection of radar Doppler profile characteristics suggests that a combination of spectral width and shape may advance boundary layer identification by HF radar. For the two December days studied the onset of radar cusp backscatter occurred within pre-existing $630.0 \mathrm{~nm}$ cusp auroral activity and appear to be initiated by sunrise, i.e. favourable radio wave propagation conditions had to develop. Better methods are put forward for analysing optical data, and for physical interpretation of HF radar data, and for combining these data, as applied to detection, tracking, and better understanding of dayside aurora. The broader motivation of this work is to develop wider use by the scientific community, of results of these techniques, to accelerate understanding of dynamic high-latitude boundary-processes. The contributions in this work are: (1) improved techniques of analysis of observational data, yielding meaningfully enhanced accuracy for deduced cusp locations; (2) a correspondingly more pronounced validation of correlation of boundary locations derived from the observational data set; and (3) a firmer physical rationale as to why the good correlation observed should theoretically be expected.
\end{abstract}

Correspondence to: $\mathbf{J}$. Moen

Department of Physics, University of Oslo, PO Box 1048,

Blindern N-0316 Oslo Norway

e-mail: jmoen@fys.uio.no
Key words: Ionosphere (ionospheric irregularities; polar ionosphere)

\section{Introduction}

All-sky cameras and SuperDARN HF radars with large fields-of-view, constitute powerful tools to study temporal and spatial behaviour of large-scale auroral and polar cap dynamics, and both techniques have proven potential for identification of magnetospheric boundary layers. Baker et al. $(1990,1995)$ combined PACE HF radar observations with DMSP particle data, and identified broad multi-component Doppler spectra to be a feature characteristic of coherent HF radar cusp backscatter. In contrast the low-latitude boundary layer (LLBL) was found to be associated with narrow single component spectra. The occurrence distribution of spectral widths peaked at $220 \mathrm{~m} \mathrm{~s}^{-1}$ in the cusp and $60 \mathrm{~m} \mathrm{~s}^{-1}$ in the LLBL. André et al. (1999) have published an important contribution to the understanding of the process whereby $\mathrm{HF}$ radar echoes from irregularities become Doppler spread, by Pc1 and Pc2 events.

Several attempts have been made to compare HF radar and optical cusp observations. Rodger et al. (1995) employed wide spectral widths as a radar cusp identifier. For the situation when IMF $B_{Z}$ was documented as negative, they found the equatorward boundary of the $\mathrm{HF}$ cusp signature to be located $0.5^{\circ}$ on average equatorward of the optical cusp. For the other case of unknown IMF conditions, the radar cusp boundary was either embedded within or located near the poleward edge of the auroral luminosity. Yeoman et al. (1997) demonstrated a near collocation of strong HF backscatter power, poleward moving auroral forms, and energy dispersed ions for a DMSP snapshot through the winter cusp above Svalbard. Milan et al. (1999) demonstrated a good correlation between CUTLASS HF backscatter and dayside $630.0 \mathrm{~nm}$ aurora along the meridian swept by the scanning 
photometer at Ny-Ålesund, Svalbard. They found a rather good collocation of the equatorward radar (defined by power) and optical cusp auroral boundaries, and that these boundaries showed the same motion.

The motivation for this work is to follow up on Rodger et al. (1995) and Baker et al. (1995) to validate the use of enhanced radar Doppler spectral widths as a cusp identifier around magnetic noon for one specific category of cusp aurora. The work is limited to type 1 cusp auroral activity. According to the classification by Sandholt et al. (1998), type 1 cusp aurora occur under predominantly southward IMF conditions, located typically south of $\sim 74^{\circ}$ MLAT, includes quasi-periodic sequences of poleward moving auroral forms (PMAFs), and is dominated by the $630.0 \mathrm{~nm}$ emission which indicates soft magnetosheath electron precipitation. The pattern of east-west movements of type 1 cusp activity is IMF $B_{Y}$ controlled (e.g. Sandholt et al., 1993; Moen et al., 1999). Moen et al. (1996) attributed the equatorward boundary of the type 1 aurora to an open LLBL, located poleward of the electron-trapping boundary. Sandholt et al. (1993) attributed the fading phase of a poleward moving type 1 auroral form to approaching the plasma mantle. LLBL, cusp and mantle precipitation regimes can be separated from each other based on differential ion energy fluxes (Newell et al., 1988), but are indistinguishable in an electron stimulated auroral display (e.g. Moen et al., 1998). Type 1 cusp aurora is interpreted as LLBL stimulated reconnection and is taken to be the auroral footprint of newly-opened magnetic flux. The transition from narrow single component to wide complex Doppler spectra of coherent HF backscatter has been proposed as a delineator of the open/closed field line boundary (Baker et al., 1995). Hence, it is reasonable to expect a good correlation between the equatorward boundaries of radar and optical auroras for type 1 cusp activity.

Two December days near the last sunspot minimum, for which simultaneous all-sky, meridian scanning photometer, and CUTLASS Finland radar observations are available above Svalbard, form the experimental basis for this study. The 2D perspective provided by radar and optical cusp morphology provides new detailed insight regarding the relationship between the radar and optical cusp aurora. Iterative examination of the data helps extract this new insight. Our first approach is to use the criterion that the spectral width is greater than or equal to $220 \mathrm{~m} \mathrm{~s}^{-1}$ in order to identify those radar gates which lie within the cusp (motivated by Baker et al., 1995; and Rodger et al., 1995). During intervals of strong backscatter echoes, the equatorward boundary of the radar cusp boundary indeed aligns very nicely with the equatorward boundary of the type 1 cusp. However, the spectral width boundary is poorly determined at the eastern and western edges of the radar cusp. Closer inspection reveals that boundary transitions usually stand out by virtue of changing shape and/ or broadening width of the Doppler spectral profiles, while transition features are spectrally more diverse than the narrow single-peak to broad multi-peak transition reported by Baker et al. (1995).
2D observations of the developing and fading phases of the radar cusp activity then lead one to further examine the underlying working principles of radar cusp observations. Coherent HF radars obtain backscatter echoes from field-aligned plasma irregularities of decametre scale length (half the radar operating wavelength). The generation mechanism of backscatter targets has not yet been agreed upon, but the literature has identified candidate processes including: gradient drift instability, shear instability, "stirring" or flux tube interchange, and current convective instability which can be viewed as a subset of gradient drift instabilities (e.g. Tsunoda, 1988; Basu et al., 1994). The latter mode includes field-aligned currents as an extra source of free energy in the context of interchange instabilities (Chaturvedi and Ossakow, 1981). The models have not yet added allowance for spatially structured mobility and conductivity due to structured particle precipitation. Under conditions for which plasma flow has a component in the direction of a density gradient, gradient drift instability is regarded as the dominant mode for driving the plasma unstable in the F-region auroral ionosphere (e.g. Ossakow and Chaturvedi, 1979; Basu et al., 1994). The typical geometry for gradient drift instabilities in the Northern Hemisphere cusp, is a density gradient towards north, a convection electric field pointing eastward and a background magnetic field pointing down. It is notable that the $\mathbf{E} \times \mathbf{B}$ gradient drift geometry will become stable upon reversing the electric field or the density gradient. Our data set contains an example consistent with the latter.

Section 2 provides a brief description of the different instrumental techniques used here. The data, consisting of type 1 cusp observations during two days, are presented in Sect. 3. The first day is December 17, 1995 and the second is December 24, 1995. In Sect. 4 the auroral characteristics are first discussed with respect to their magnetospheric origin and located relative to the polar cap boundary. Then the correlation between the equatorward radar and optical cusp boundaries are studied, and transition features in the Doppler power spectra across cusp activity boundary are examined. Finally, various aspects of radar cusp and formation of backscatter are illuminated. A brief summary and concluding remarks are presented in Sect. 5.

\section{Instrumentation}

\subsection{CUTLASS Finland HF radar}

The CUTLASS Finland radar located at Hankasalmi $\left(62.3^{\circ} \mathrm{N}, 26.6^{\circ} \mathrm{E}, 58.62^{\circ} \mathrm{CGMLAT}\right)$ has an array of 16 antennas, with both transmitting and receiving capabilities. The radar can operate in the HF band between $8 \mathrm{MHz}$ and $20 \mathrm{MHz}$. The antennas in each array are phased relative to one other so as to form an antenna pattern in which maximum gain (beam position) has one of 16 azimuthal pointing directions separated by approximately $3.2^{\circ}$, distributed symmetrically about the radar boresite of $-12^{\circ}$ (i.e. west of geographic north). 
Svalbard is located near the centre of the fan-shaped field-of-view.

CUTLASS is a coherent HF radar which measures backscatter echoes from field-aligned plasma irregularities in the high-latitude ionosphere (e.g. Greenwald et al., 1995). A 7 pulse scheme is transmitted, and analysis of the auto-correlation function (ACF) of the return signals yields backscatter Doppler spectra, from which the spectral characteristics of power, line-of-sight Doppler velocity and spectral width can be derived (e.g. Hanuise et al., 1993; Baker et al., 1995). F-region backscatter echoes serve as a tracer of $\mathbf{E} \times \mathbf{B}$ convection of plasma (Villain et al., 1985; Ruohoniemi et al., 1987; Davies et al., 1999).

The actual radar field-of-view depends strongly on the ionospheric conditions for radio wave propagation. Due to the Earth's curvature, the propagation mode for ionospheric backscatter from above Svalbard must be multi-hop, and is most likely the $11 / 2 \mathrm{~F}$ mode HF radiowave propagation. The $1 \frac{1}{2} \mathrm{~F}$ mode means that the radar signal has been first refracted by the F-region ionosphere to a ground point, then reflected forward into a second hop, during which some energy is backscattered from F-region irregularities. Far range backscatter is only possible if the ionospheric refraction conditions produce the first hop, followed by forward scatter that reaches a more distant scatterer. Refraction depends on the transmitted frequency and on the ionospheric plasma density distribution (vertically and horizontally along the propagation path). This has been discussed in detail by Milan et al. (1997).

On December 17, 1995, the radar scanned through beams 12 to 5 in descending order, returning to beam 9 between each, with a dwell time of $7 \mathrm{~s}$, producing a fieldof-view map of backscatter every 2 min. A total of 75 range gates were sampled for each beam with a pulse length of $100 \mu \mathrm{s}$, corresponding to the gate length of $15 \mathrm{~km}$. The lag to the first gate is $8700 \mu \mathrm{s}$ and the range coverage is from $1305 \mathrm{~km}$ to $2430 \mathrm{~km}$. On December 24, 1995, the radar scanned through beams 13 to 7 in descending order. Again 75 range gates were sampled for each beam but with a pulse length of $200 \mu \mathrm{s}$, corresponding to the gate length of $30 \mathrm{~km}$. The lag to the first gate is $5800 \mu \mathrm{s}$ and the range coverage is from $870 \mathrm{~km}$ to $3120 \mathrm{~km}$.

\subsection{MSP and ASI}

The $630.0 \mathrm{~nm}$ aurora were surveyed by a meridian scanning photometer (NYA MSP) operated at NyAlesund $\left(78.9^{\circ} \mathrm{N}, 11.9^{\circ} \mathrm{E}, 76.07^{\circ} \mathrm{CGMLAT}\right)$ and an allsky imager (ASI) located at Longyearbyen $\left(78.2^{\circ} \mathrm{N}\right.$, $\left.15.8^{\circ} \mathrm{E}, 75.12^{\circ} \mathrm{CGMLAT}\right)$. The MSP has a $2^{\circ}$ field of view and sweeps the magnetic meridian to $10^{\circ}$ above the northern and southern horizons every $18 \mathrm{~s}$. Longyearbyen ASI measured a $630.0 \mathrm{~nm}$ image every $45 \mathrm{~s}$. Longyearbyen and Ny-Ålesund are located at nearly the same magnetic longitude, crossing magnetic local noon at $\sim 0850$ UT. To represent a common MSP and
CUTLASS field-of-view, radar gates were selected from beam 7-12 projected along the MSP scan-line.

\subsection{NOAA and WIND spacecraft}

NOAA-12 and NOAA-14 are low-altitude polar orbiting satellites operating at an $\sim 820 \mathrm{~km}$ altitude above the Earth's surface. The satellites carry two complements of particle instruments, the total energy detector (TED) and the medium energy proton and electron detector (MEPED). TED measures electrons and ions between 0.3 and $20 \mathrm{keV}$, in two viewing directions, one toward zenith and the other $30^{\circ}$ to zenith. This instrument has been designed to obtain the energy flux moment, but also provides crude electron and ion energy spectra as well. MEPED consists of solid-state detector telescopes: one pointing toward zenith to view particles that precipitate into the ionosphere, the other at $90^{\circ}$ to zenith to view particles that will magnetically mirror above the atmosphere. The energy ranges sensed are for electrons $>30 \mathrm{keV},>100 \mathrm{keV},>300 \mathrm{keV}$, all with a $1000 \mathrm{keV}$ maximum energy, and for ions $30-80 \mathrm{keV}$, 80-250 keV, $250-800 \mathrm{keV}, 800-2500 \mathrm{keV}$ and $>2500$ $\mathrm{keV}$. Employing the criteria established by Moen et al. (1996), the integral number flux of precipitating 300$460 \mathrm{eV}$ electrons and $0.3-2.35 \mathrm{keV}$ ions from TED's zenith-look will be used as an indicator of soft magnetosheath-type precipitation. MEPED provides information on energetic magnetospheric particle fluxes $(>30 \mathrm{keV})$ and helps locate the electron trapping boundary.

The WIND spacecraft is used to monitor solar wind conditions upstream of the bow shock. We will present data from two of the eight instruments carried by WIND: the magnetic field investigation (MFI), and the solar wind experiment (SWE). Detailed descriptions can be found in Lepping et al. (1995) and Ogilvie et al. (1995), respectively.

\section{Observations}

\subsection{December 17, 1995}

Figure 1 displays WIND observations of solar wind conditions for the 07 to $11 \mathrm{UT}$ interval. The panels in this figure show from top to bottom: the antisunward velocity and density of the solar wind plasma, and the magnitude and three GSM components of the IMF. WIND was located upstream of the Earth at $(59,32,0)$ $R_{E}$ in XYZ GSM co-ordinates. Milan et al. (1999) estimated a time lag of 16 to 24 min between IMF observations and the ionospheric response for this. The time lag is sensitive to the $B_{X}$ to $B_{Y}$ ratio when the spacecraft is located far off the Sun-Earth axis upstream (Lockwood et al., 1989). When the satellite operates on the duskside upstream as here, a positive (negative) $B_{X}$ to $B_{Y}$ ratio will shorten (increase) the time lag compared to the nominal value based on the antisunward solar wind plasma speed and the distance along the Sun-Earth 


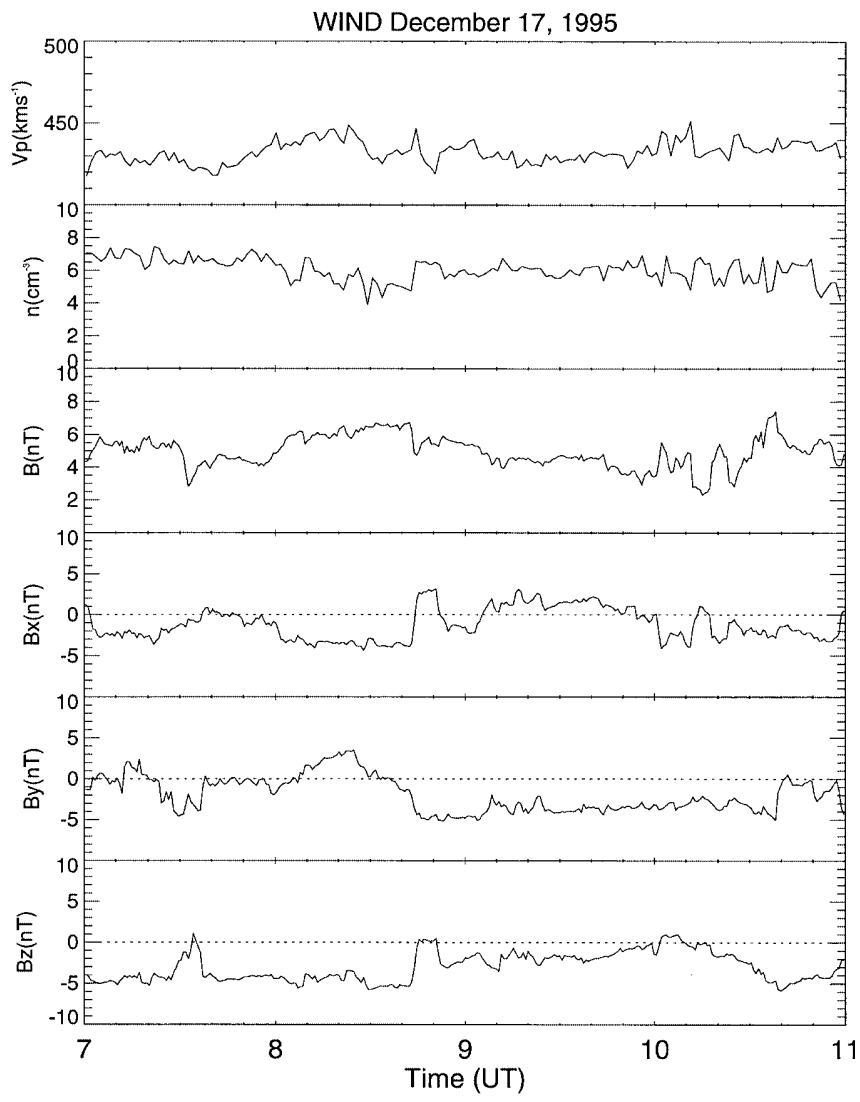

Fig. 1. Solar wind plasma and IMF data measured by WIND on December 17, 1995

axis. The $B_{X}$ to $B_{Y}$ ratio changed sign several times during the $08-10$ UT interval of primary interest for this study. Such sign reversals, combined with expectation of a nominal time lag of $\sim 20 \mathrm{~min}$, notably aid identification of auroral responses to major IMF transitions.

Figure 2 presents Ny-Ålesund MSP and CUTLASS Finland radar data recorded between 0830 and $1100 \mathrm{UT}$. The top panel shows $630.0 \mathrm{~nm}$ emission intensity versus scan-angle and time, while the three panels below it show spectral width, backscatter power and line-of-sight velocity versus CGMLAT and time. The black contour line marks the equatorward boundary of the red line auroral activity. A numerical computer code was developed for automatic tracing of the arc boundary, for objectivity, and meaningful consistency, in addition to convenience. The code definition used for the boundary is where the second derivative of the zenith angle variation of emission intensity reaches zero, i.e. where the gradient of emission intensity maximises. This will later be referred to as the maximum gradient method. In order to compare auroral activity with HF radar backscatter echoes, the equatorward boundary of auroral activity has been converted to CGMLAT and overlayed on the radar parameter plots in Fig. 2. The height of the $630.0 \mathrm{~nm}$ border was taken to be $215 \mathrm{~km}$ for reasons that will be discussed in Sect. 4.2. The code traced the equatorward boundary perfectly well up to 1045 UT after which the derived boundary became ragged. To illustrate temporal changes in the (particle energy) spectral content of the auroral activity, peak values of $630.0 \mathrm{~nm}$ (solid line) and $557.7 \mathrm{~nm}$ (dotted line) observed during each MSP sweep is plotted versus time in Fig. 3. The aurora is reddominated up to about 1010 UT after which the $557.7 \mathrm{~nm}$ intensity curve started fluctuating about the $630.0 \mathrm{~nm}$ curve, and soon after became substantially larger than the red line. As this work is devoted to HFbackscatter related to red-dominated dayside aurora, attention is drawn to observations before $1010 \mathrm{UT}$.

From 0830 to 0855 UT in Fig. 2 a relatively faint auroral band is located between $130^{\circ}$ to $150^{\circ}$. This quiet aurora is associated with poor backscatter (only a few range gates of weak power). From 0855 to 0900 UT, the auroral boundary migrated southward from $150^{\circ}$ to $155^{\circ}$ scan-angle corresponding to $73^{\circ}$ to $72^{\circ}$ CGMLAT, associated with a significant increase in emission intensity. This is a likely response to the IMF $B_{Z}$ stepping down from -3.5 at 0825 UT to -6 nT at 0830 UT (i.e. $\sim 30$ min time lag which make sense as the $B_{X}$ to $B_{Y}$ ratio was positive). Strong backscatter (a band of high backscatter power) developed at auroral latitudes and the activity are associated with line-of-sight flows in the range from 0.5 to $1 \mathrm{~km} \mathrm{~s}^{-1}$. Another activity increase at 0915 UT is seen in the upper panel of Fig. 2, and this time is associated with the onset of a sequence of PMAFs. Between the two activity enhancements at 0900 and $0915 \mathrm{UT}$, the equatorward boundary migrated poleward from $155^{\circ}$ to $150^{\circ}$ scan-angle, which is consistent with the gentle rise in IMF $B_{Z}$ from -6 at 0830 UT to $-5 \mathrm{nT}$ at $0843 \mathrm{UT}$. IMF $B_{Y}$ was weak, but notably it underwent a polarity change from positive to negative during the same time interval. The latter activity change at 0915 UT is attributed to the sharp rotation of IMF from south to east in the course of a couple of minutes. The increasing strength of negative IMF $B_{Y}$ is expected to shift the cusp location dawnwards (see. Moen et al., 1999). Figure 4a presents a sequence of all-sky images from 0850 to $0940 \mathrm{UT}$ in $\sim 10 \mathrm{~min}$ intervals. The colour scale is linear with increasing intensity from blue to red. The yellow squares superimposed onto the all-sky images mark position of the radar gates with spectral width $\geq 220 \mathrm{~m} \mathrm{~s}^{-1}$. Backscatter with insufficient signal to noise ratio were discarded when employing the spectral width filtering on the data. This cut-off was taken to be the $0 \mathrm{~dB}$ at lag 0 in the ACF. All-sky imagery reveals that the two discrete enhancements in activity level seen by the MSP at 0900 and $0915 \mathrm{UT}$, were both related to activity enhancements surging across the scan-meridian from the east. With the latter surge, pulsed cusp-like (red-dominated) aurora became established across the full fieldof-view. A sequence of four major PMAFs is seen in the upper panel of Fig. 2 from $\sim 0915$ to 1005 UT.

Strong backscatter developed within the auroral zone from 0900 UT onwards (see the second and third panel of Fig. 2). Up until about 1005 UT the auroral zone backscatter have large spectral widths colour-coded from light green to red, i.e. larger than $250 \mathrm{~m} \mathrm{~s}^{-1}$. In Fig. 4a, high-spectral width backscatter $\left(\geq 220 \mathrm{~m} \mathrm{~s}^{-1}\right)$ initially occurred as a patch associated with brightening 

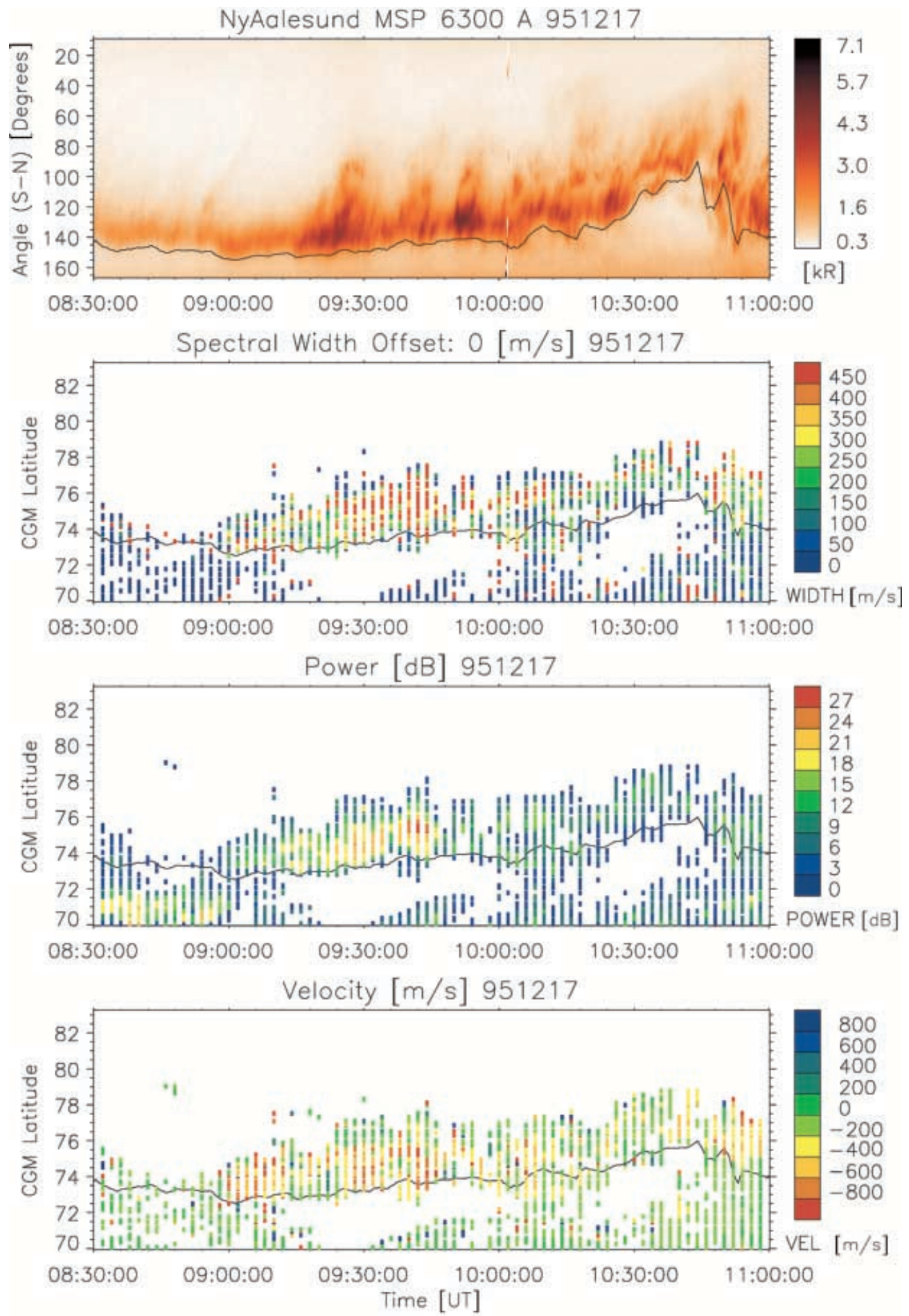

Fig. 2. The top panel shows $630.0 \mathrm{~nm}$ emission intensity observed by NYA MSP versus zenith angle and time for December 17, 1995. The three panels below show spectral width, backscatter power, and the lineof-sight velocities obtained by the CUTLASS Finland radar versus CGMLAT and time with a 2-min time resolution. Positive (negative) velocities indicate motion towards (away) from the radar. CUTLASS radar gates along the sweep line of the photometer have been selected for the comparison. The black line in each panel represents the equatorward boundary of the $630.0 \mathrm{~nm}$ activity of the optical aurora south of Svalbard around 9 UT; 10 min later, the patch of radar cusp backscatter has expanded eastwards and polewards. Strong backscatter became established across the full radar field-of-view at the time when the 0915 UT surge of pulsed cusp activity expanded into the field-of-view from east. The spectral width boundary lines up remarkably well with this, and clearly follows the dynamics of the equatorward auroral boundary. The radar cusp backscatter typically extends north of the optical aurora. The all-sky observations are continued in Fig. 4b for another half hour. Note that Fig. $4 \mathrm{~b}$ contain $630.0 \mathrm{~nm}$ images in the upper row, and simultaneous $557.7 \mathrm{~nm}$ images in the bottom row. From 1000 UT onwards the spectral width boundary ceases to be collocated with the auroral boundary, but instead is located well south of it. By comparing the red line (upper row) and green line images (bottom row), a prominent transition is noticed from red-dominated broad activity region in the western half to a greendominated discrete arc in the eastern part of the camera 


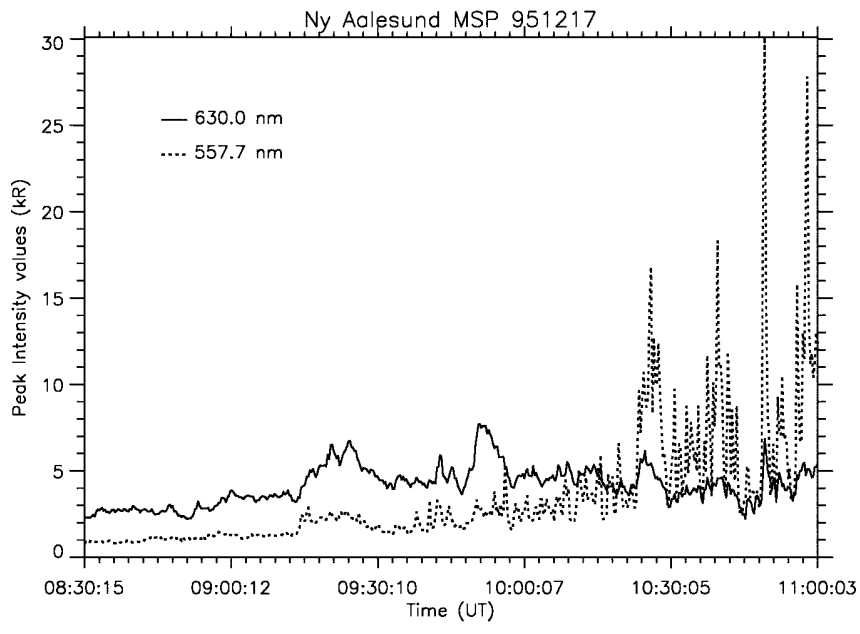

Fig. 3. Peak intensity values of $630.0 \mathrm{~nm}$ (dotted line) and $557.7 \mathrm{~nm}$ (solid line) observed along each north-south scan by NYA MSP versus time on December 17, 1995. Note that the $630.0 \mathrm{~nm}$ and $557.7 \mathrm{~nm}$ traces do not necessarily come from the same field line, and is only meant to be a qualitative indicator of the red versus green line dominance across the band of auroral activity

field-of-view. The camera was not intensity calibrated and the transition from $630.0 \mathrm{~nm}$ to $557.7 \mathrm{~nm}$ auroral activity was identified from the MSP observations (Fig. 3). There is a trend for the spectral width boundary to line up poleward of the discrete arc.

\subsection{December 24, 1995}

Figure 5 shows solar wind conditions probed by WIND at a location $(31,-37,0) R_{E}$ in XYZ GSM co-ordinates for the time interval 07-11 UT. The magnitude of IMF was strongly varied between 10-20 nT and the field orientation underwent rapid changes several times. The active cusp auroral conditions on this day is related to the IMF observations from about 0840 to $1025 \mathrm{UT}$, when $B_{Z}$ fluctuated from weakly positive to strongly negative and $B_{Y}$ experienced a series of polarity changes from $\pm 15 \mathrm{nT}$. Moen et al. (1999) studied the cusp auroral response to the IMF $B_{Y}$ polarity change from negative to positive at $\sim 0938$ UT and documented a duskshift of the cusp position. The time lag from WIND to the auroral response of this particular discontinuity was estimated to be $\sim 15 \mathrm{~min}$. The time lag is subject to variation as the satellite was located far east of the SunEarth axis, and the IMF $B_{X}$ to $B_{Y}$ ratio underwent rapid variations. For this case when the satellite is located on the dawnside upstream, a positive (negative) $B_{X}$ to $B_{Y}$ ratio will increase (shorten) the time lag compared to the nominal value. The $B_{X}$ to $B_{Y}$ ratio was negative for the 15 min time lag estimated by Moen et al. (1999).

Figure 6 surveys MSP and CUTLASS observations for 0830-1100 UT. The narrowing and intensification of the background arc at 0905 UT is a likely response to the southward turning of IMF observed by WIND $\sim 20$ min earlier. From 0905 to 0955 UT a sequence of 5 PMAFs is outstandingly clear, being formed in the quasi-steady narrow background arc and subsequently moving poleward. After 1010 UT the equatorward edge of the aurora migrated southward beyond the MSP field-of-view, which made tracking of the arc boundary impossible. A significant increase in the emission intensity occurred at 1020 UT. At $\sim 1035$ UT, the arc split into a high- and a low-latitude component, resembling a cusp bifurcation as described by Sandholt et al. (1998), which is an expected response to the sharp northward turning of IMF at $\sim 1020$ UT. Figure 7 shows the $630.0 \mathrm{~nm}$ (solid line) and $557.7 \mathrm{~nm}$ (dotted line) peak intensities measured by the MSP for the same interval as in Fig. 6. The auroral activity was strongly red-dominated throughout the time interval.

Strong backscatter developed within the auroral oval at 0925 UT, i.e. a few minutes after the first two PMAFs. The radar back-scatter straddles the equatorward boundary of $630.0 \mathrm{~nm}$ luminosity, and it is strikingly clear that the spectral width enhancement boundary is collocated and moves together with the auroral arc boundary up until 1010 UT, i.e. until the MSP lost sight of the arc boundary. At 1020 UT, an abrupt change occurred in the radar backscatter. A simultaneous decrease in backscatter power and narrowing of spectral width took place associated with a decrease in line-of-sight velocities. As will be discussed in Sect. 4.4, this may address the IMF $B_{Z}$ polarity change at around 10 UT. Furthermore, the periods of strong line-of-sight velocities away from the radar consistent with poleward flows centred on $\sim 0930$ and $\sim 10$ UT in the bottom panel of Fig. 6 are likely controlled by the negative bays in IMF $B_{Z}$ centred on $\sim 0910$ and $\sim 0945$ UT (Fig. 5).

Figure $8 \mathrm{a}, \mathrm{b}$ demonstrates 2D observations of radar and optical aurora for the time interval from 0918.531020.26 UT. As for the December 17 case, the yellow squares mark radar gate locations of spectral widths $\geq 220 \mathrm{~m} \mathrm{~s}^{-1}$. The first four images in Fig. $8 \mathrm{a}$ are $\sim 2 \mathrm{~min}$ apart and illustrate how backscatter develops in relation to the active aurora. No clear correlation between auroral intensity and HF backscatter spectra is apparent at this early stage. In the first image (0918.53 UT) radar cusp backscatter are seen east of the most intense optical aurora, but develop across the entire CUTLASS field of view within $6 \mathrm{~min}$ (see the 0924.08 UT image). The bright aurora displayed in the 0932.24 UT image happened to be the first PMAF in the sequence associated with strong backscatter (see Fig. 6). When strong backscatter has developed, the spectral width boundary lines up and intimately follow the equatorward border of the optical cusp, except for a some sporadic gates of possible ground-clutter further south. The mismatches seen in the 1004.40, 1012.55 and 1018.55 UT images are a combined effect of camera sensitivity decreasing towards the limb and motion of the arc boundary out of the camera field-of-view. An IMF $B_{Y}$ regulated dusk-shift of the cusp location, as reported by Moen et al. (1999), is apparent in Fig. 8b. The last expansion, moving in from a cusp location south-west of Svalbard, is seen in the 0948.54 UT image. Thereafter cusp auroral forms drifted westwards across the field-of-view from a new location southeast of 
Svalbard. One such brightening is seen in the 0956.25 UT image, and the east-west dynamics of a subsequent event from this new location is illustrated in the bottom row in Fig. 8b. When $B_{Z}$ is weak and $B_{Y}$ strong, pulsed cusp auroral events propagate east-west and within the auroral band, and do not appear as PMAFs in Fig. 6. The radar cusp backscatters do not seem to be particularly sensitive to the east-west dynamics of the optical aurora, but rather remain strong until their abrupt turn-off at $\sim 1020$ UT. In association with the IMF $B_{Z}$ negative bays and PMAFs, the radar cusp backscatter notably extend much further into the polar cap than the optical aurora.

\section{Discussion}

\subsection{Boundary layer sources}

From Fig. 2, we recall that on December 17 the aurora was diffuse from 0830 to $0915 \mathrm{UT}$, with a discrete step increase in intensity at 0855 UT corresponding to a discrete step decrease in the $B_{Z}$ component of IMF. The second major activity change occurred at 0915 UT in response to an IMF $B_{Y}$ regulated westward shift of the auroral activity centre, seen by the MSP as the onset of pulsed activity including the sequence of PMAFs. The third activity change seen by the MSP began at $\sim 1005$ UT, as a change in optical spectral content with decreasing $630.0 \mathrm{~nm}$ and increasing $557.7 \mathrm{~nm}$ emission intensities (see Fig. 3). At this time Svalbard was located underneath a transition from pulsed red-dominated aurora on the west side to intense $557.7 \mathrm{~nm}$ discrete arc aurora on the east side (Fig. 4b). NOAA-12 flew over Svalbard around 0841 UT cutting through the stable arc of relatively faint $630.0 \mathrm{~nm}$ aurora. The key particle signatures probed were similar to those Moen et al. (1996) and Lockwood and Moen (1996) attributed to open LLBL. The particle data (not presented here) can be described as follows: the red-dominated aurora were populated by a high flux of magnetosheath-type origin (integral fluxes of 300-460 eV electrons and 0.3 $2.35 \mathrm{keV}$ ions, see Sect. 2.3) and a modest flux of isotropic magnetospheric ions and electrons $(>30 \mathrm{keV}$, see Sect. 2.3). The equatorward edge of the auroral arc was collocated with a sharp cut-off in the magnetosheath component bordering on the $100 \mathrm{keV}$ electron trapping boundary. The characteristic electron energy within the arc was at or below the $300 \mathrm{eV}$ sensitivity threshold of TED, while the ion energy was $3 \mathrm{keV}$ at the equatorward border, exhibited a sharp decrease with latitude, and dropped to the energy threshold level of $300 \mathrm{eV}$ during the arc crossing. The pulsed red-dominated activity west of Svalbard around 1010 UT was probed by NOAA-14 along the path illustrated in red in the bottom right frame of Fig. 4b. Particle characteristics similar to those of the NOAA-12 pass were measured (data not presented here). The red aurora was again populated with magnetosheath-type particles. The ion energy decreased from $8 \mathrm{keV}$ to $1 \mathrm{keV}$ with increasing latitude across the arc, and the equatorward arc boundary and magnetosheath particle cut-off were again located poleward of the $100 \mathrm{keV}$ electron trapping boundary. In accordance with the cumulative knowledge of polar cap boundary phenomena and the IMF control of the auroral morphology, the magnetosheathlike particle injection with energy dispersed ions poleward of the electron trapping boundary are key characteristic signatures of open LLBL/cusp field lines (Lockwood et al., 1998). The discrete $557.7 \mathrm{~nm}$ arcs extending from the pulsed cusp/cleft aurora into the post-noon sector are likely footprints of R1 currents of BPS origin. This interpretation is in accord with the first of two possibilities outlined by Milan et al. (1999) who based their interpretation on assumed locations of the open/closed field line boundary. Keep in mind that the main objective of Milan et al. (1999) was to study boundary motions and flow excitation.

For the December 24 case, we limit our interest to the 0905-1035 UT interval of ionospheric observations, corresponding to predominantly IMF $B_{Z}$ south conditions with a series of sharp polarity changes in IMF $B_{Y}$. The auroral morphology is intimately regulated by the IMF orientation and constitutes as such a prime example of type 1 cusp auroral activity according to Sandholt et al. (1998). Sequences of PMAFs and strong poleward flows occur in response to negative bays in IMF $B_{Z}$, whereas east-west movements take over during periods when IMF $B_{Y}$ dominates. Moen et al. (1999) documented the IMF $B_{Y}$ regulation of the convection pattern and the longitudinal location of the activity centre. The high $630.0 \mathrm{~nm}$ to $557.7 \mathrm{~nm}$ intensity ratio throughout this interval provides another firm indication of magnetosheath particle injections along IMF connected field lines. Unfortunately, there were no suitable DMSP or NOAA crossings to calibrate the precipitation source on December 24.

Experience has shown that the LLBL, cusp and mantle precipitation regimes cannot be distinguished from each other in an electron stimulated auroral display (Moen et al., 1998; Sandholt et al., 1998). However, the most essential boundary when studying solar-terrestrial interactions is the open-closed field line boundary. Based on the established criteria for open LLBL/cusp signatures, the radar cusp backscatter seen from 09-10 UT on December 17 and from 0920 and 1010 UT on December 24, bounded by the $630.0 \mathrm{~nm}$ activity on the equatorward side, occurred on opened magnetic field lines. Our observations are in analogy with Pilkington et al. (1975) who reported a near collocation between the poleward HF curtain and the poleward trapping boundary for $>40 \mathrm{keV}$ electrons.

\subsection{Correlation between the CUTLASS $\geq 220 \mathrm{~m} \mathrm{~s}^{-1}$ spectral width boundary and $630.0 \mathrm{~nm}$ boundary observed by MSP}

In order to compare radar and optical cusp boundary locations, a first step is to determine scan-angle position of the $630.0 \mathrm{~nm}$ arc boundary, after which the scanangle position must be transformed to the same 

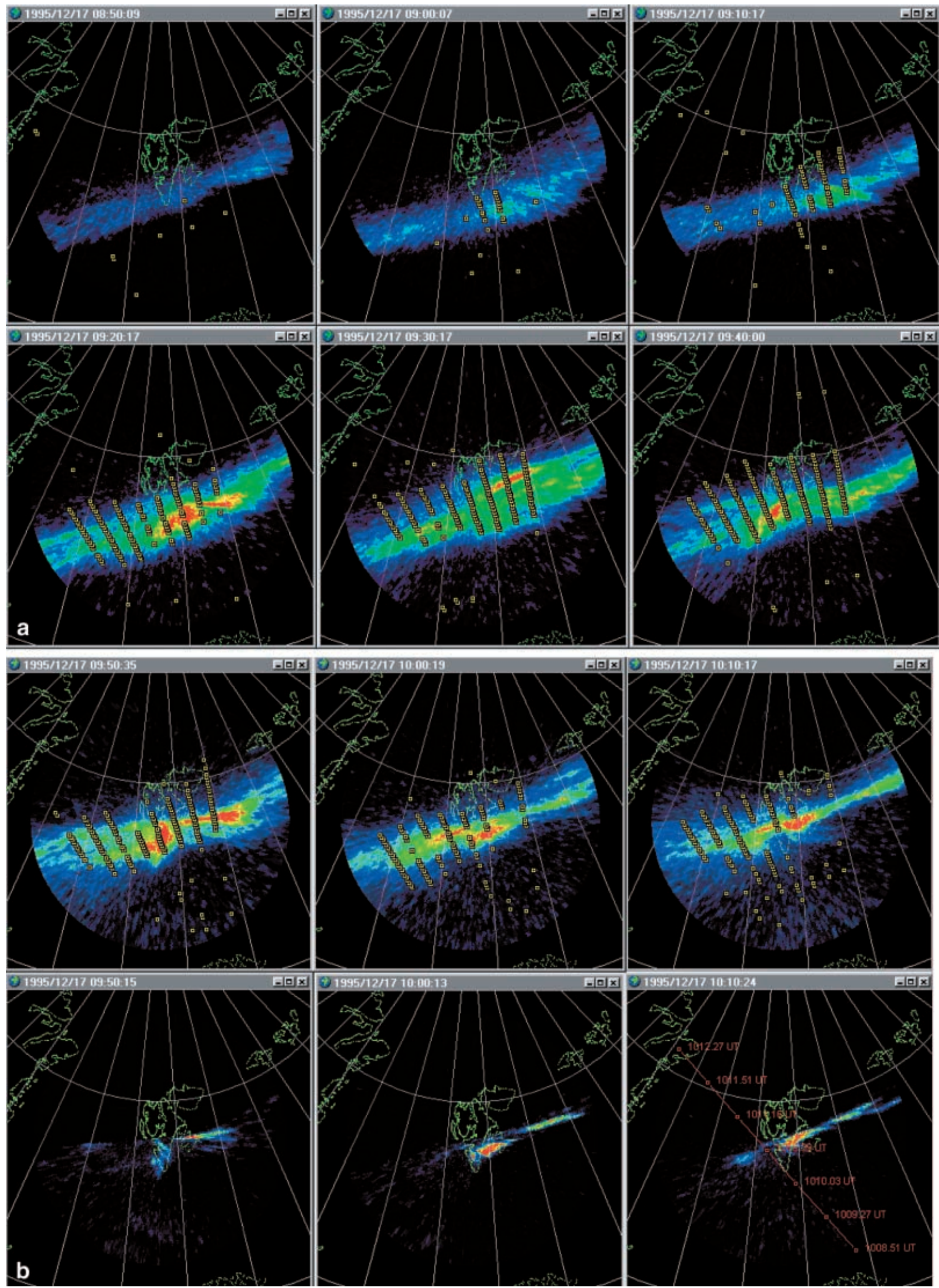
Fig. 4. a Selected colour-coded (ranging from blue to red with increasing intensity) all-sky images of the $630.0 \mathrm{~nm}$ aurora for the period 0850.09 UT to 0940.00 UT on December 17, 1995. The auroral emission is mapped onto a geographical grid assuming an emission altitude of $215 \mathrm{~km}$. The images have been cut at $75^{\circ}$ zenith angle. The yellow squares mark positions of gates with spectral widths $\geq 220 \mathrm{~m} \mathrm{~s}^{-1}$ along CUTLASS Finland beams 5-11 from west to east. b The upper row shows colour-coded all-sky images of the $630.0 \mathrm{~nm}$ aurora for the period 0950.35 UT to 1010.17 UT, and the bottom row shows corresponding images of the $557.7 \mathrm{~nm}$ aurora. An emission height of $150 \mathrm{~km}$ has been assumed for the $557.7 \mathrm{~nm}$ emission, and these images have been cut at $80^{\circ}$ zenith angle. Please note that the camera was not absolute calibrated and the colour coding should not be inter-compared. The red line in the bottom right panel indicates the trajectory of a NOAA-14 pass

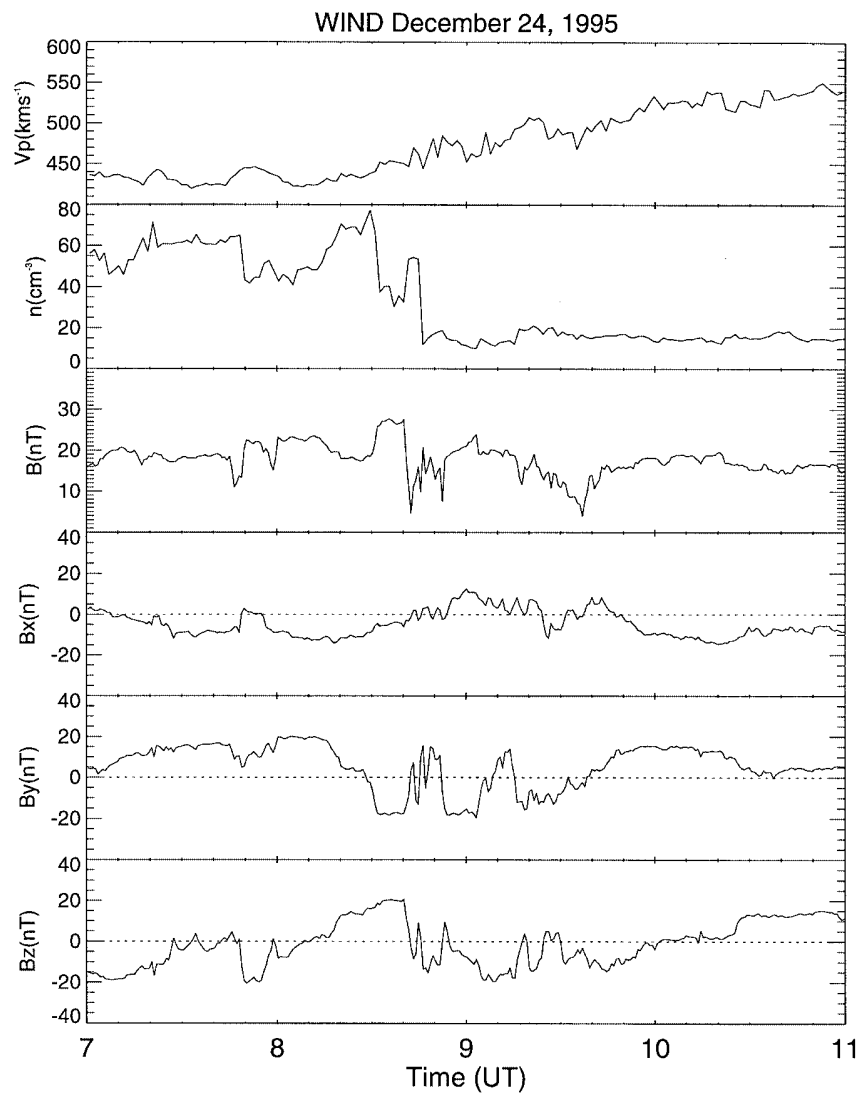

Fig. 5. Solar wind plasma and IMF data measured by WIND on December 24, 1995

CGMLAT co-ordinate reference as used for the radar observations. The latter step involves an educated guess as to the emission altitude. The NYA MSP system has not been developed for subtracting background luminosity and Milan et al. (1999) chose an intensity isocontour level to represent the $630.0 \mathrm{~nm}$ arc boundary. However, as the background intensity may differ considerably from one day to another, the isocontour intensity has to be set manually for each data set. During observation intervals of hours the background luminosity may be subject to large changes, which lead to systematic offsets of the chosen isocountour boundary from the actual precipitation boundary. The max- imum gradient method used here is insensitive to background luminosity and very reliably traces the equatorward boundary of $630.0 \mathrm{~nm}$ cusp activity. This improvement limits uncertainty in the arc boundary location to only that associated with the assumption of the $630.0 \mathrm{~nm}$ emission altitude. Furthermore, when the auroral band is located south of the observation site as here, the equatorward boundary is the southern bottom edge of the arc being scanned. Then the auroral height assumption is reduced to only estimating the emission cut-off height, a task with inherently much smaller uncertainty (it involves uncertainties of a fraction of the molecular scale height at relatively low temperatures, rather than of atomic scale heights at relatively high temperatures). Overall this dramatically reduces the uncertainty in boundary location, the scale height effect alone reducing the uncertainty to less than half. The average energy of cusp electrons is less than $220 \mathrm{eV}$, but energies typically ranges from few tens of $\mathrm{eV}$ to $\sim 500 \mathrm{eV}$ (Newell and Meng, 1988). The stopping altitudes for mono-energetic electron beams of $100 \mathrm{eV}, 200 \mathrm{eV}$ and $400 \mathrm{eV}$, are $320 \mathrm{~km}, 250$ and $200 \mathrm{~km}$, respectively (see e.g. Millward et al., 1999). Allowing for both excitation by precipitating electrons and quenching by molecular species the $630.0 \mathrm{~nm}$ emission will confine the expected peak-emission altitude to $\sim 225-300 \mathrm{~km}$. Millward et al. (1999) pointed out that the emission altitude may increase with latitude inside the cusp, from considerably lower than $250 \mathrm{~km}$ at the equatorward edge to nearer $300 \mathrm{~km}$ at the poleward edge, this due to energy dispersion. Hence, the emission cut-off height is expected not higher than $250 \mathrm{~km}$.

The aim of this work was to check whether enhanced spectral widths can serve as a marker of the cusp boundary. In the top panel of Fig. 9 the southernmost gate position of spectral widths $\geq 220 \mathrm{~m} \mathrm{~s}^{-1}$ has been plotted as a function of the $630.0 \mathrm{~nm}$ auroral boundary, assuming emission altitude of $250 \mathrm{~km}$ for both the data sets. The plot includes only the periods of a wellestablished radar cusp boundary within the MSP field of view, i.e. from 09-10 UT on December 17 and from 0920 and 1010 UT on December 24 (see Figs. 2 and 6).

We would like to emphasise that the band of highpower cusp backscatter is associated with high spectral widths, i.e. that the equatorward edge of high $\left(\geq 220 \mathrm{~m} \mathrm{~s}^{-1}\right)$ spectral widths nearly coincide with the equatorward edge of steeply enhanced backscatter power as demonstrated by Milan et al. (1997). The boundary motions for December 17 and 24 are clustered around 71 and 73.5 CGMLAT, respectively. On both days the auroral activity was situated south of the MSP observation site located at 76 CGMLAT. The full line depicts a least-square fit representation of the two data sets, and the dashed line serves as a guideline to colocation of the two boundaries. The trend is a clear. The gap between the two boundaries increases with latitude, with the radar cusp edge located poleward of the optical cusp boundary. If there were any physical relationship between the precipitation boundary and the radar cusp boundary, one might have expected that the distance between the two boundaries should be independent of 

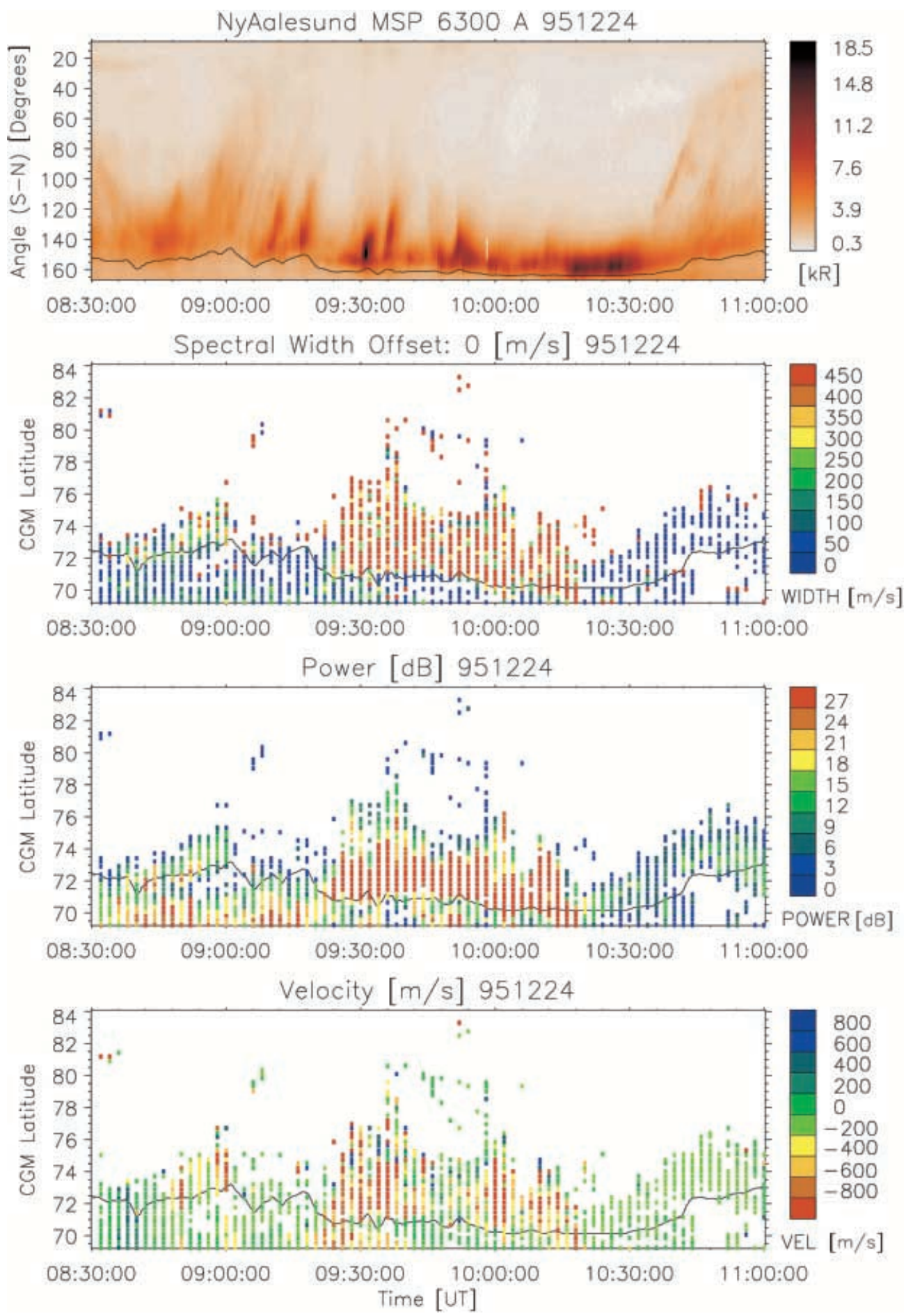

Fig. 6. NYA MSP and CUTLASS observations for 0830-1100 UT on December 24, 1995. Same format as in Fig. 2

latitude, as would result from adjusting the emission height. On December 17 the aurora was less reddominated than on December 24. This indicates that the electron precipitation was somewhat harder and in turn suggests a lower emission height on December 17 compared to December 24. The bottom panel of Fig. 9 illustrates the effect of lowering the emission height from $250 \mathrm{~km}$ to $215 \mathrm{~km}$ for this December 17 data. The correlative coefficient, $r$, remained nearly unchanged (0.962115 versus. 0.963262). Lowering the altitude is based on physics. The altitude to which it was lowered is based on obtaining latitude independence of the separation between the best fit line (dashed) and the solid line indicating boundary co-location. Latitude independence could also have been achieved by increasing the emission height on the December 24 data, but a bottom emission altitude of higher than $250 \mathrm{~km}$ at the equatorward cusp edge seems unrealistic (Millward et al., 1999).

The large spread of data points $( \pm 1$ degree latitude $= \pm 110 \mathrm{~km}$ ) about the best fit line seem to worsen with latitude, if there is any latitude dependence to be found. If the spread were due to a time varying emission 


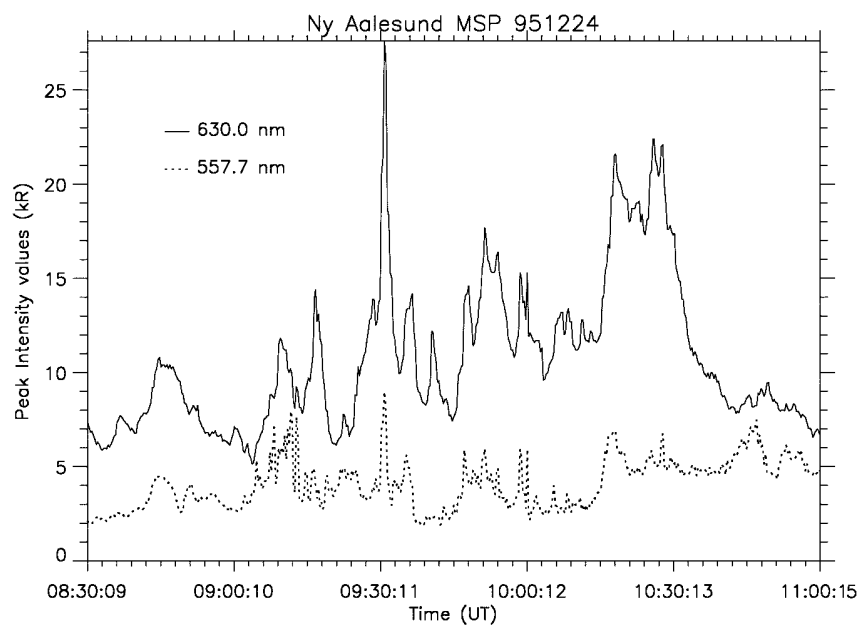

Fig. 7. Peak intensity values of $630.0 \mathrm{~nm}$ (dotted line) and $557.7 \mathrm{~nm}$ (solid line) observed along each north-south scan by NYA MSP versus time on December 24, 1995

altitude of the $630.0 \mathrm{~nm}$ emission, the spread would have diminished towards the MSP site of 76 CGMLAT. A random variation in emission altitude between 215$250 \mathrm{~km}$ would introduce a scatter in auroral boundary location of $\sim 0.7^{\circ}$ around 70.5 CGMLAT $\left(5^{\circ}\right.$ in latitude south of Ny-Alesund) and $\sim 0.4^{\circ}$ around 73.5 CGMLAT $\left(2.5^{\circ}\right.$ in latitude south of $\mathrm{Ny}$-Ålesund). The quite opposite trend in latitude spread around the best fit lines in Fig. 9 indicates that the spread is rather being introduced by the physical nature of radar cusp backscatter/ radio wave propagation, e.g.: (1) uncertainty in the geographic location of the radar echoes; (2) the $220 \mathrm{~m} \mathrm{~s}^{-1}$ criterion used for the radar cusp boundary; (3) the generation mechanism of plasma irregularities.

Point (1) is related to the fact that we do not know the exact radio wave propagation path. Range determination performed by the radars is based on the time-offlight of radar returns. This provides an accurate measure of the length of the group path taken by the radar signal (also known as slant range or radar range), but this is an overestimate of the ground range to the scatter volume. A detailed knowledge of the electron density distribution within the radar's propagation environment would allow a ray-tracing analysis to transform from radar range to ground range accurately. Without this detailed knowledge, however, assumptions must be made regarding the characteristics of the propagation mode to the scatter volume. Such considerations, specifically whether radar signals propagate by the $0.5-\mathrm{F}$ mode or $1.5-\mathrm{F}$ mode, have been discussed at some length by Milan et al. (1997, 1998): near- and farrange scatter is expected to propagate by the $0.5-\mathrm{F}$ and 1.5-F modes, respectively. For simplicity our analysis of SuperDARN data assumes that all echoes are $0.5-\mathrm{F}$ mode returns, that signals propagate at the speed of light in vacuo, and that the ray path is a straight line, that is the effect of refraction is neglected. These assumptions tend to overestimate the range to more distant scatter if a realistic scattering altitude $(\sim 250 \mathrm{~km})$ is used in the calculations, so to overcome this we further assume that the scatter originates from the artificially high altitude of $400 \mathrm{~km}$. This compromise is found to work well for most ranges, though the inaccuracy increases with greater distance. The accuracy of our range determination can be tested with the Tromsø high power radio wave facility which artificially stimulates ionospheric irregularities at a known altitude and location from which the CUTLASS radars receive coherent backscatter (see e.g. Wright and Yeoman, 1999). At a range of $2000 \mathrm{~km}$, the assumptions employed in the routine analysis discussed lead to a systematic overestimate in the range to the heater volume of some $60 \mathrm{~km}(\mathrm{~T}$. K. Yeoman, personal communication, 2000). This represents the first and only direct measurement of absolute range by a SuperDARN radar, but other studies have investigated the range accuracy between different propagation modes. These include: Milan et al. (1998) who examined a case in which propagation to the dayside auroral zone changed sharply between the $0.5-\mathrm{F}$ and 1.5 $\mathrm{F}$ mode with little discernable change in range being observed; André et al. (1997) who compared observations at different radar operating frequencies and demonstrated a range consistency of the order of $45 \mathrm{~km}$ or one standard range gate; and modelling work by Villain et al. (1985) which again estimated that range uncertainty was of the order of $45 \mathrm{~km}$ or less. Our overall conclusion is that for the distances of interest in the present study the range uncertainty due to the radar data analysis is no larger than $60 \mathrm{~km}$ (corresponding to four $15 \mathrm{~km}$ gates on December 17 and two $30 \mathrm{~km}$ range gates on December 24) and that this is likely to be an overestimate of the true range. Furthermore, for each event this overestimate will be systematic, that is the equatorward boundary of cusp backscatter, which is of particular interest for this study, will be displaced in latitude but its shape should remain essentially unchanged. We note in fact from Figs. 4 and 8 that the $630.0 \mathrm{~nm}$ and spectral width boundaries are very similar in shape, even when the boundary is undulating or changing. Thus, uncertainties in mapping the slant range to geographic location are expected to shift the boundary location by $\sim 40-60 \mathrm{~km}$, but are not expected to cause scatter of $\pm 1^{\circ}$ as is the case in Fig. 9. Hence, we suggest that this spread is caused mainly by points (2) and (3) which will be illuminated further in Sect. 4.3 and 4.4 .

\subsection{Radar cusp discriminating criteria}

The general trend seen from the 2D morphology (Figs. 4 and 8 ) is that once strong backscatter has developed at latitudes of red-dominated cusp aurora, the equatorward edges of the $220 \mathrm{~m} \mathrm{~s}^{-1}$ spectral width boundary and optical auroras are closely collocated and show the same motion. This indicates that the $\geq 220 \mathrm{~m} \mathrm{~s}^{-1}$ spectral width criterion serve as a robust filter to delineate the cusp activity boundary albeit there are some problems, in particular at the east and west ends of radar cusp activity (perhaps associated with geometry of viewing angle). Figure 10a-d shows radar Doppler spectra along 

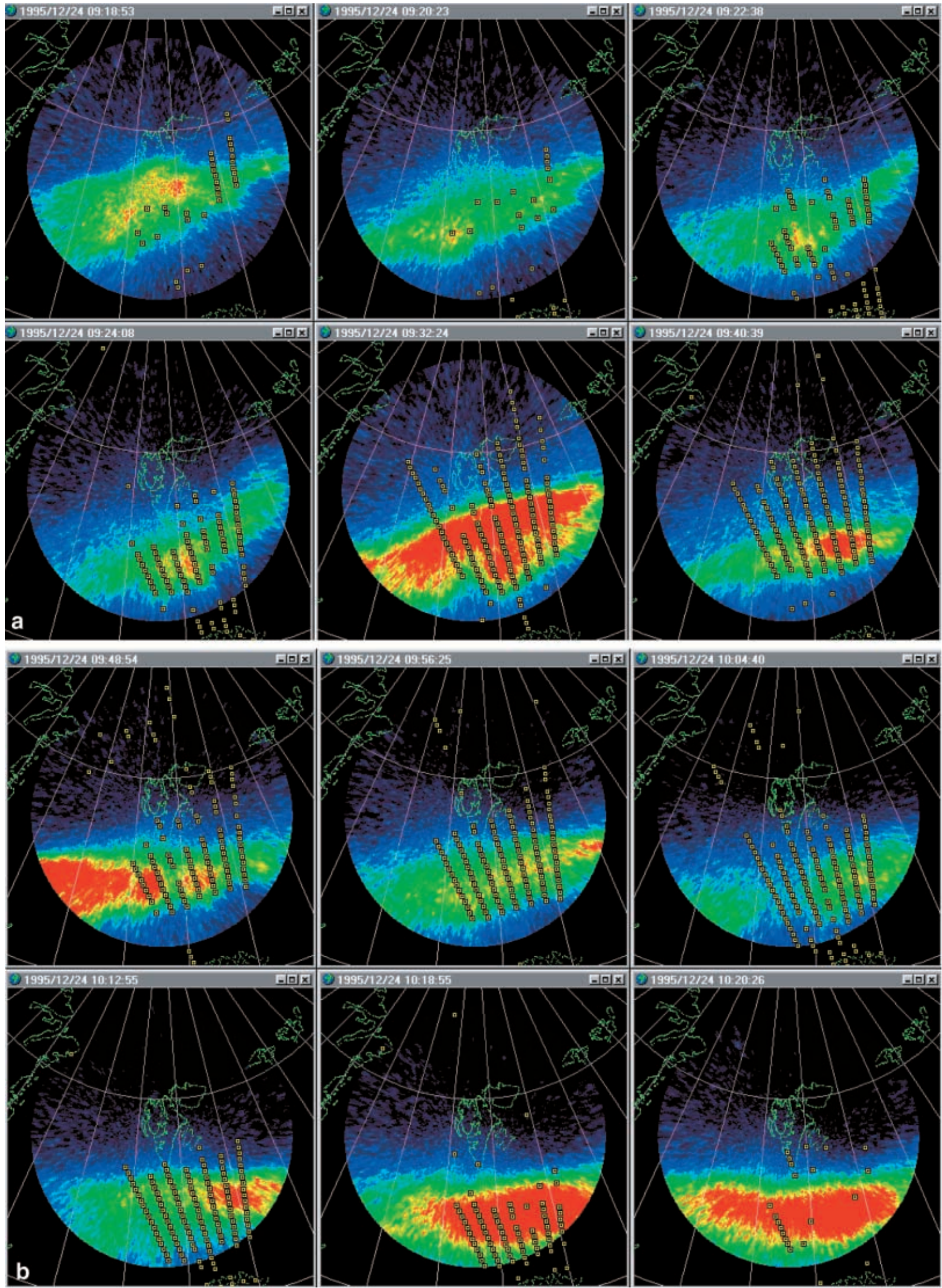
Fig. 8.a A sequence of colour-coded (blue to red with increasing intensity) $630.0 \mathrm{~nm}$ all-sky images for the 0918.53-0940.39 UT interval on December 24, 1995. The yellow squares mark positions of gates with spectral widths $\geq 220 \mathrm{~m} \mathrm{~s}^{-1}$ along CUTLASS Finland beams 7-13 from west to east. $\mathbf{b}$ A continuation of $\mathbf{a}$
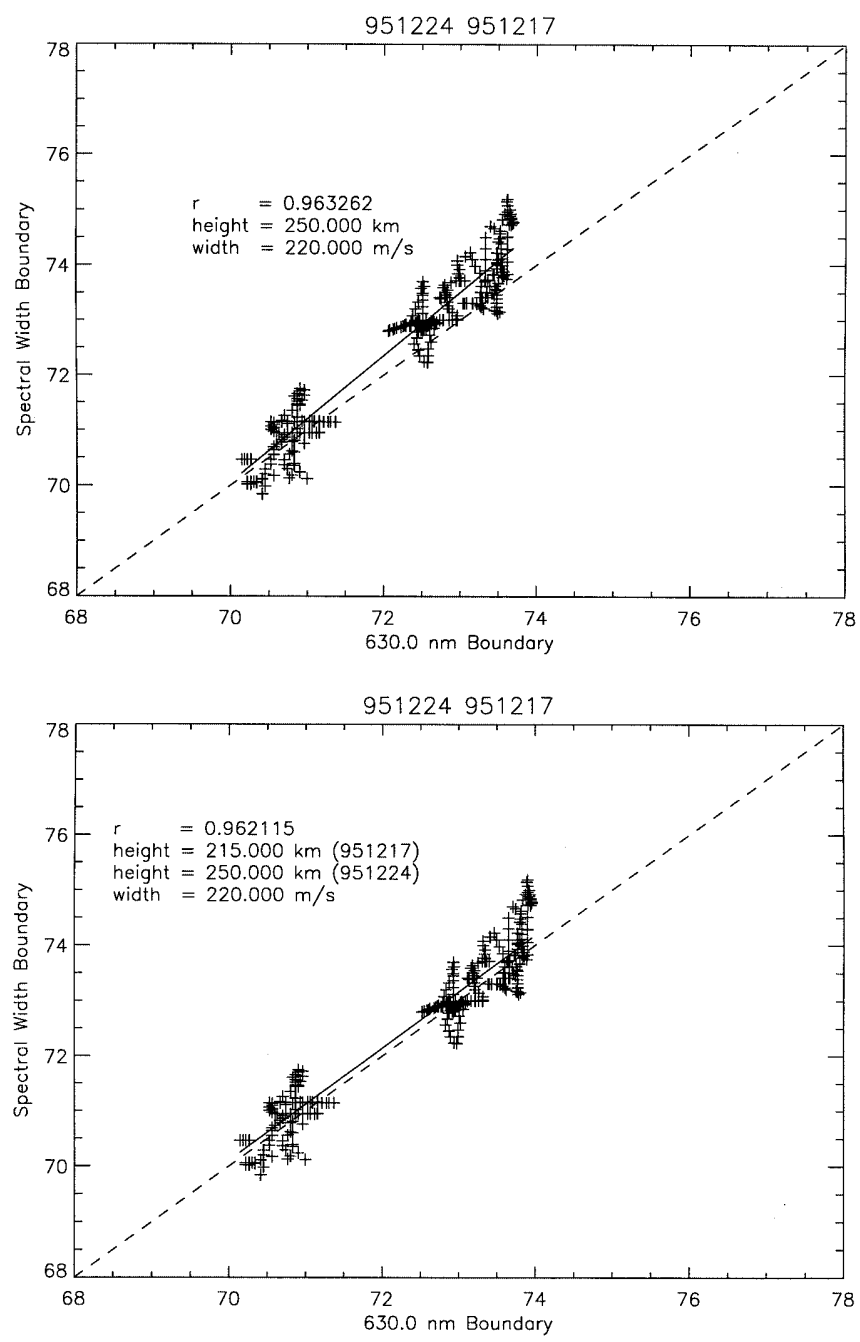

Fig. 9. The location of the equatorward edge of the $630.0 \mathrm{~nm}$ cusp and CUTLASS HF radar cusp for 09-10 UT on December 17 and 0920-1020 UT on December 24, 1997. The difference between the upper and the lower panel is that the auroral emission height has been lowered from $250 \mathrm{~km}$ to $215 \mathrm{~km}$ on December 17. The solid line in each diagram represent the least square fit to both data sets, and the broken line serves as a guideline for radar and $630.0 \mathrm{~nm}$ boundary colocation. See Sect. 4.2 for details

individual radar beam crossings of the cusp activity boundary, so we shall now consider boundary transition features in the spectra. Each spectrum has been selfnormalised and the bar on the right side in each frame provides a crude indicator of the backscatter power. Figure 10a displays spectra from gates 15 to 30 along beam 9 sampled at 0910.43 UT on December 17. Beam 9 corresponds to the fourth beam stripe from right in the 0910.17 UT frame of Fig. 4a, i.e. related to the developing phase of radar cusp backscatter. The five yellow square gate positions south of the auroral arc corre- spond to gates 16, 20-22 and 24, and gate 27 collocates with the auroral boundary. Gates 15, 17-19, 23, 25-26 were all discarded by the $\geq 220 \mathrm{~m} \mathrm{~s}^{-1}$ filtering and/or poor signal to noise ratio. For this particular case the radar cusp boundary is marked by the transition from a multi-peak to a single-peak spectrum. The backscatter power levels of gates 27-30 embedded in the optical aurora are higher than gate 26 and below. The low backscatter power south of gate 27 may imply that spectra there are susceptible to noise and interference, which may account for the complex form of the spectra there. Figure 10b shows Doppler power spectra along beam 7 corresponding to the third beam stripe from left in the 1010.17 UT frame of Fig. 4b, and represent an example of an unclean boundary near the postnoon end of cusp aurora. The yellow squares in Fig. $4 \mathrm{~b}$ from south to north along the beam stripe mark locations of gate $9,19,25-26,28,30,34-41,43-53$ and 58. Letting our eye be guided by the $630.0 \mathrm{~nm}$ activity boundary we take gate 34 as being representative of the radar cusp boundary. Again the spectral width criterion failed to pick the boundary, which in this case stands out as an apparent change in the spectral shape, from a single peak to a broad artificial spectrum. The spectra of gates 34 and 35 look synthetic and are likely an artefact of the signal processing (see discussion later). The backscatter power remained high across the cusp activity boundary. Figure $10 \mathrm{c}, \mathrm{d}$ presents radar power spectra from gate 15-30 along beam 10 and beam 11 corresponding to the fourth and the fifth beam stripes from left in the 0932.24 UT frame of Fig. 8a. Let us first consider beam 10 in the 0932.24 UT frame of Fig. 8a. The five gate positions seen south of the arc correspond to gates $11-$ 13 (not shown) and 15-16 (shown) in Fig. 10c. These are all single peaked spectra with spectral widths larger than $220 \mathrm{~m} \mathrm{~s}^{-1}$. Gate 19 is the one that collocates with the arc boundary. However, the apparent change in spectral shape seen from a narrow single-peak in gate 17 to a multi-peak in gate 18 may suggest gate 18 to be a marker for the radar-cusp cleft boundary. Gate 18 was discarded due to a bad signal to noise ratio. A notable increase in backscatter power occurred at gate 20 north of the auroral boundary. The broad and smoothed spectra at gates 19 and 21 are suggested to be an artefact of the signal processing. Gates 22-26 within the aurora provide good examples of broad complex spectra with high power and hence not susceptible to noise/interference problems that may influence the spectral shapes when the backscatter power is low. Along beam 11 we see a prominent transition from narrow single peaked spectra from below gate 19 to broad spectra of various shapes from gate 19 and above. Gate 19 is the southernmost gate in the third beam stripe from left in the 0932.24 UT frame of Fig. 8a, and again, it is an artificially shaped spectrum that lines up with the optical boundary. It is also seen that a significant increase in power occurs at the fourth gate north of the boundary.

Before we continue, in a similar manner, to inspect more CUTLASS Doppler spectra later, let us pause to consider the nature of the HF coherent backscatter 
a
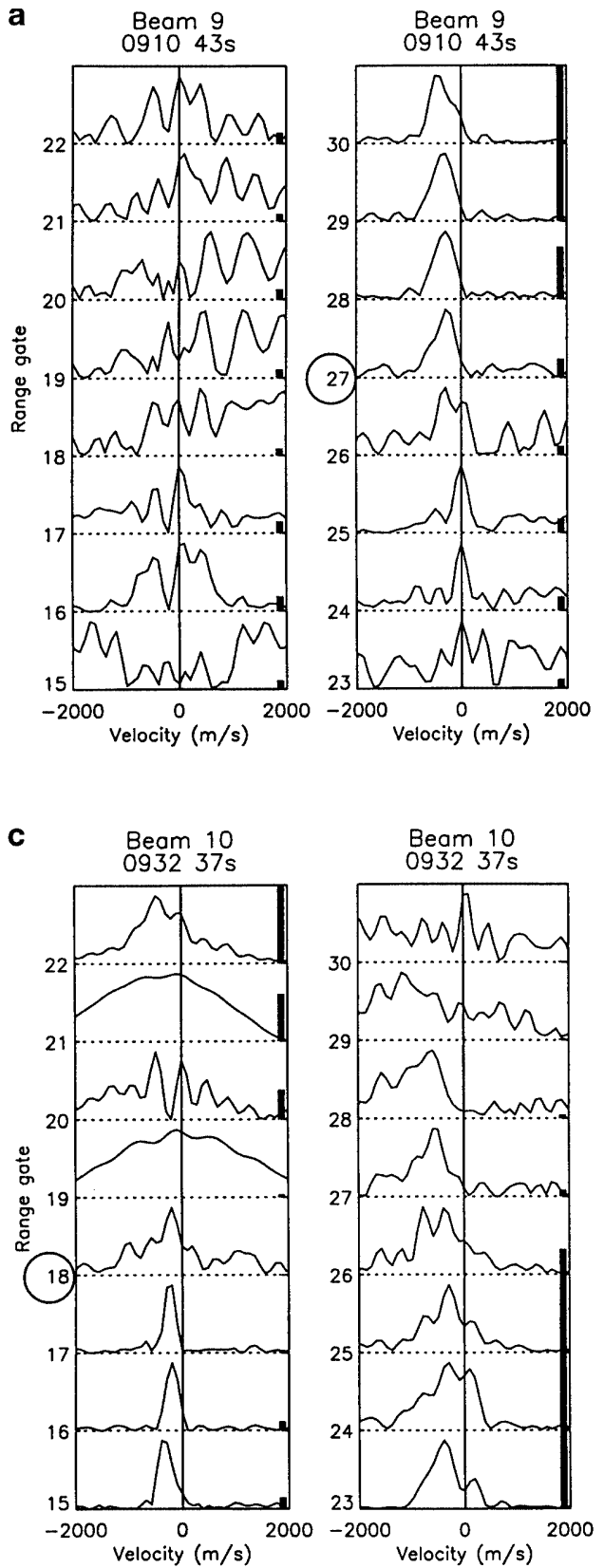

b

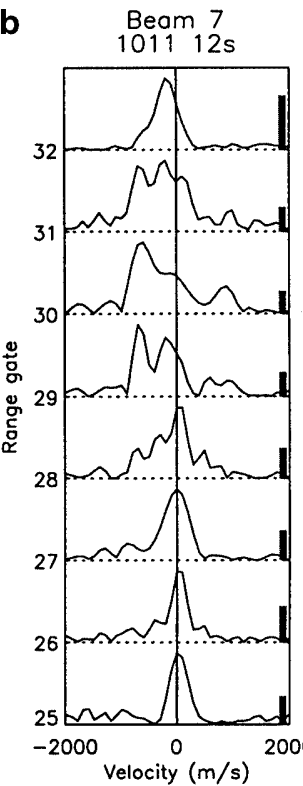

d

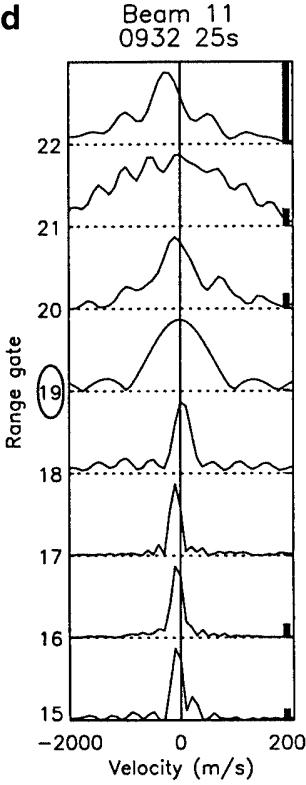

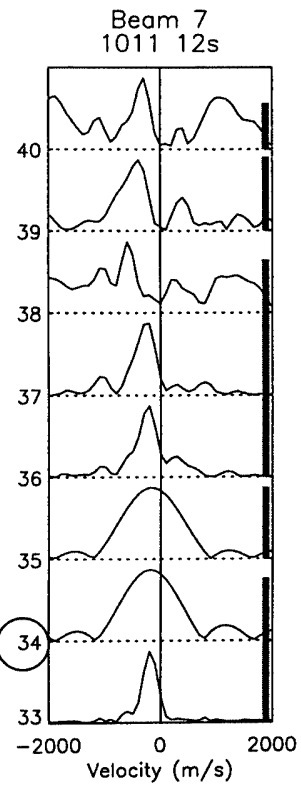

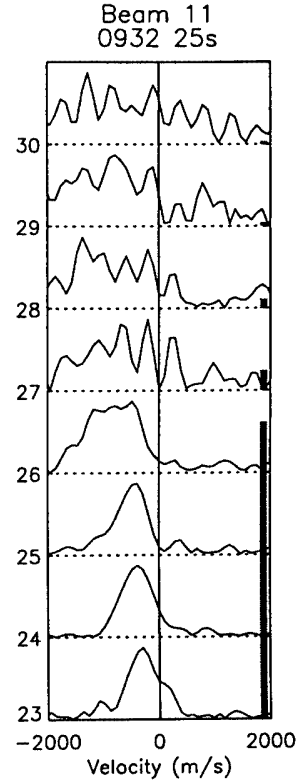

Fig. 10a-d. Radar Doppler power spectrums along a selection of beams. Each spectrum has been self-normalised and the bar to the right of each spectrum indicates backscatter power. The gate number circled is the most equatorward cusp gate along each beam. See Sect. 4.3 for a full explanation echo. It has been known for some considerable time that strong field-aligned plasma density structures are found in the cusp, and it has thus been natural to explore HF coherent echoes as a means of detection of the cusp. The $\mathrm{HF}$ echo comes from the total number of discrete coherent scatterers within the radar illuminated volume. If within a radar range resolution cell (volume defined by the radar pulse length and radar beam envelope), there are several scatterers all moving with identical velocity component along the radar line-of-sight, all these echoes will: (a) have the same Doppler shift; (b) appear at the same spectral shift; and (c) add to a clean narrow echo. However, André et al. (1999) demonstrated that this idealised picture may be significantly disturbed by the electric field noise commonly observed in the cusp (e.g. Maynard et al., 1991; Basinska et al., 1992). They simulated HF-observations of randomly disturbed scatterers totally correlated but subjected to Pc1-Pc2 wave activity. This was to investigate the possible effect on HF radar ACFs of the step-like increase of the $0.2-2.2 \mathrm{~Hz}$ band activity observed collocated with the cusp precipitation boundary (Erlandson and Anderson, 1996; Dyrud et al., 1997). Their simulation results reveal that the broad multi-peaked cusp spectra may indeed be stimulated by the Pc1-Pc2 wave perturbation of the velocity field. This is an artefact of under-sampling, i.e. that the radar sampling rate is less than the Nyquist frequency.

"Artificial spectra" (e.g. at range gates 34-35 in Fig. 10b) are usually a consequence of an inherent system limitation. Once a pulse is transmitted, the receivers are to record the return signal for a length of time equivalent to the time taken for the signal to propagate to the maximum radar range and back again. 
This, however, is longer than the inter-pulse spacing, and when the subsequent pulse is transmitted the receivers have to be turned off for a short duration. This leads to "bad lags" at some ranges (range gates). When the number of "bad lags" at a particular range become too great, the ACF becomes poorly defined, especially if strong backscatter power occurs at other range ranges ("cross-range" noise). These poorly defined ACFs lead to synthetic spectra. This happens preferentially at certain gates, e.g. 19 (Fig. 10c, d) and 34-35 (Fig. 10b). If too few lags are available the data are usually discarded by the ACF fitting analysis.

Other contamination sources will on occasion occur as well. These will include both generic, e.g. ground clutter, and system specific with details dependent on the particular system and environment, e.g. receiver characteristics and ray propagation paths. The raw data shown here thus also have to have some limited number of range gates eliminated from consideration in the comparison. These were few enough to negligibly impact the findings, and having no asymmetry led to no bias of the findings.

Let us now return to further examination of the HF radar echo characteristics, and their relationship to optical boundaries, for the remaining data presented here. We have manually inspected 17 more radar beam intersections of the cusp activity boundary and the observations are coded in Table 1 . Column 3 and 4 yield spectral width and spectral shape of the southernmost cusp radar gate. $\mathrm{Y}, \mathrm{N}$, or $\mathrm{YH}$ in the third column refers to the fulfilment of the $220 \mathrm{~ms}^{-1}$ spectral width criterion and stand for yes, no, or yes but high spectral widths across the boundary, respectively. S, M, or A in the fourth column refers to single-peak, multi-peak or artificial shape, respectively. The fourth column codes the transition in spectral shape across the boundary (the boundary marker gate has been compared to the neighbouring gate south of), e.g. S-M means a transition from single to multi-peak, and $\mathrm{N}$ stands for no transition. The fifth column describes change in backscatter power across the boundary, where y(es) means enhanced power, and NH and NL indicates $\mathrm{n}(\mathrm{o})$ change in power, power stayed either h(igh) or $1(\mathrm{ow})$. The spectral width enhancements readily appear to be the most characteristic feature of the cusp activity boundary. It should be noticed however that the boundary marker gate of enhanced spectral width may have all various shapes and cannot always be subscribed a physical meaning. On December 24 in particular, the good correlation between the spectral width enhancement boundary and the optical cusp boundary was aided by a well-defined sharp transition from narrow single peak to broad synthetic spectra. In four of the 21 cases the spectral width stayed high across the cusp auroral boundary. In the first of these four cases a transition was seen in both shape and power, and in the last of them, a transition was seen only in the spectral shape. For the other two cases, a boundary was not apparent in the radar data at all. In most cases the backscatter power stayed low (NL) across the cusp boundary but a steep increase was seen a few gates
Table 1. The first column gives sampling time for the beam number in the second column. Third column describes the southernmost gate of cusp activity with respect to the spectral width criterion, where $\mathrm{Y}$ (yes) means $\geq 220 \mathrm{~m} \mathrm{~s}^{-1}$, $\mathrm{N}$ (no) means $<220 \mathrm{~m} \mathrm{~s}^{-1}$, and $\mathrm{YH}$ (yes high across) means that also the neighbouring gate south of the cusp boundary had a spectral width $\geq 220 \mathrm{~m} \mathrm{~s}^{-1}$. Fourth column describes the shape of the radar Doppler spectrum of the southernmost gate of cusp activity, where S, M, A, are codes for single peak, multi-peak, artificial shape, respectively. The fifth column describes the transition in shape across the cusp boundary, where e.g. M-S means a transition from multiple to single peak, and $\mathrm{N}$ stands for no change in shape. The sixth column specifies change in power across the boundary, $\mathrm{Y}$ for enhanced power, $\mathrm{NH}$ for no change power stays high and NL for no change power stays low

\begin{tabular}{llllll}
\hline $\begin{array}{l}\text { Time } \\
\text { (UT) }\end{array}$ & $\begin{array}{l}\text { CUTLASS } \\
\text { beam }\end{array}$ & $\geq 220 \mathrm{~m} \mathrm{~s}^{-1}$ & $\begin{array}{l}\text { Spectral } \\
\text { shape }\end{array}$ & $\begin{array}{l}\text { Shape } \\
\text { transition }\end{array}$ & $\begin{array}{l}\text { Enhanced } \\
\text { power }\end{array}$ \\
\hline $\begin{array}{c}\text { December } 17,1995 \\
0910.43\end{array} \quad 9$ & & & & \\
0919.59 & 11 & $\mathrm{YH}$ & $\mathrm{M}$ & $\mathrm{M}-\mathrm{S}$ & $\mathrm{Y}$ \\
0920.14 & 12 & $\mathrm{Y}$ & $\mathrm{S}$ & $\mathrm{N}$ & $\mathrm{NL}$ \\
0930.14 & 11 & $\mathrm{Y}$ & $\mathrm{M}$ & $\mathrm{S}-\mathrm{M}$ & $\mathrm{NL}$ \\
0930.00 & 12 & $\mathrm{Y}$ & $\mathrm{S}$ & $\mathrm{N}$ & $\mathrm{Y}$ \\
0941.12 & 7 & $\mathrm{Y}$ & $\mathrm{S}$ & $\mathrm{N}$ & $\mathrm{NH}$ \\
0940.57 & 8 & $\mathrm{Y}$ & $\mathrm{S}$ & $\mathrm{N}$ & $\mathrm{Y}$ \\
0951.12 & 7 & $\mathrm{YH}$ & $\mathrm{M}$ & $\mathrm{S}-\mathrm{M}$ & $\mathrm{NL}$ \\
0950.57 & 8 & $\mathrm{Y}$ & $\mathrm{M}$ & $\mathrm{N}$ & $\mathrm{NL}$ \\
1000.43 & 9 & $\mathrm{YH}$ & $\mathrm{S}$ & $\mathrm{N}$ & $\mathrm{NL}$ \\
1011.12 & 7 & $\mathrm{YH}$ & $\mathrm{A}$ & $\mathrm{S}-\mathrm{A}$ & $\mathrm{NH}$ \\
& & & & \\
December 24,1995 & & $\mathrm{Y}$ & $\mathrm{M}$ & $\mathrm{N}$ & $\mathrm{NL}$ \\
0924.50 & 9 & $\mathrm{Y}$ & $\mathrm{M}$ & $\mathrm{N}$ & $\mathrm{NL}$ \\
0924.37 & 10 & $\mathrm{Y}$ & $\mathrm{M}$ & $\mathrm{S}-\mathrm{M}$ & $\mathrm{NL}$ \\
0932.37 & 10 & $\mathrm{Y}$ & $\mathrm{A}$ & $\mathrm{S}-\mathrm{A}$ & $\mathrm{NL}$ \\
0932.25 & 11 & $\mathrm{Y}$ & $\mathrm{A}$ & $\mathrm{S}-\mathrm{A}$ & $\mathrm{NL}$ \\
0940.49 & 9 & $\mathrm{Y}$ & $\mathrm{A}$ & $\mathrm{N}$ & $\mathrm{Y}$ \\
0940.37 & 10 & $\mathrm{Y}$ & $\mathrm{A}$ & $\mathrm{S}-\mathrm{A}$ & $\mathrm{NL}$ \\
0948.37 & 9 & $\mathrm{Y}$ & $\mathrm{A}$ & $\mathrm{N}$ & $\mathrm{NL}$ \\
0948.50 & 10 & $\mathrm{Y}$ & $\mathrm{A}$ & $\mathrm{S}-\mathrm{M}$ & $\mathrm{NL}$ \\
0956.50 & 9 & $\mathrm{Y}$ & $\mathrm{M}$ & $\mathrm{S}-\mathrm{M}$ & $\mathrm{NL}$ \\
0956.38 & 10 & $\mathrm{Y}$ & $\mathrm{M}$ & & \\
\hline
\end{tabular}

further north of the auroral cusp boundary. We interpret this as due to finite growth rate times of plasma irregularity formation (see Sect. 4.4 for more details). For the 21 cases in Table 1 we counted 341 gates of enhanced spectral widths north of the cusp boundary. Of these gates $67 \%$ had broad multi-peak, $20 \%$ broad single peak and $13 \%$ broad artificial spectra. It is beyond the scope of this study to systematically examine whether an identifiable signal to noise ratio can be defined, below which the multipeaked spectra are so low in power that they are susceptible to noise/interference and become unreliable as indicators of boundaries.

Baker et al. (1995) found LLBL to be largely associated with single-peak spectra and the complex multi-peak spectra were addressed to cusp/mantle. As was pointed out in Sect. 4.1 by ground-based optical measurements we are not able to discriminate between cusp and LLBL. It may well be that the broad singlepeak Doppler spectra address open LLBL. The diffuse east-west edges of the radar cusp aurora reported by Baker et al. (1995) is consistent with our observations (see Figs. 4 and 8). 


\subsection{Formation and drifts of radar backscatter irregularities}

Radar cusp backscatter developed within the band of pre-existing $630.0 \mathrm{~nm}$ emissions both days. Bearing in mind that two conditions are to be met for $\mathrm{HF}$ backscatter to occur: (1) favourable radio wave propagation conditions, and (2) field aligned irregularities. The onset on December 17 may appear to accompany intensification of the optical aurora. However, that is clearly not the case on December 24 . The IMF $B_{Z}$ regulated onset of PMAFs occurred $\sim 15$ min prior to the development of radar cusp, and the radar cusp initially formed east of the brightest region of $630.0 \mathrm{~nm}$ luminosity (demonstrated by the upper left image in Fig. 8a). A successful "first hop" is mandatory for CUTLASS Finland to receive far range echoes from above Svalbard. Refraction (ray path) conditions are determined by the operating frequency and the F2 layer density profile (e.g. Milan et al., 1997). According to the backscatter occurrence statistics conducted by Milan et al. (1997) for the same winter (1995/96), CUTLASS illumination of the ionosphere at Svalbard latitudes is typically limited to a $3 \mathrm{~h}$ interval starting at $\sim 10 \mathrm{UT}$. CUTLASS operated at the same frequency range $(9.915$ to $9.985 \mathrm{MHz}$ ) both days, and if the onset time is regulated by radio wave propagation conditions, we are left with the build up of $F$ region plasma density to feed the near-noon $\mathrm{F}$ layer as the major controlling factor. This means that the solar zenith angle must be sufficiently high to accumulate adequate bottomside $\mathrm{F}$ region plasma densities for propagation path connectivity, and that corrotational or other transport of these plasma densities place them with reasonable repeatability in line with the propagation path from the CUTLASS Finland transmitter site and the cusp reflection region above Svalbard. The solar zenith angle referred to Longyearbyen was $-12.8^{\circ}$ at the onset December 17 (0900 UT) and $-12.7^{\circ}$ on December 24 (0920 UT), very repeatable and adequate for bottomside plasma to build up. The reflection height for the CUTLASS radar propagation path from the Finland site is at sufficiently low latitude $\left(\sim 62.5^{\circ}-63.5^{\circ}\right.$ CGMLAT) that the bottomside plasma densities at the local times here would be reasonably expected to reproduce on these two days. Thus, this is consistent with the simple interpretation that $\mathrm{F}$ region density for propagation connectivity was the "switch" for seeing the turn on of HF echoes, rather than the turn on of the irregularities themselves.

Three fundamentally different mechanisms are presently thought to comprise the set of processes by which cusp irregularities are produced, although it is not known which one(s) dominate for particular common conditions. The gradient drift plasma instability mechanism is known to occur for plasma drift, of only the right sign, across a steep plasma density gradient (perpendicular to the magnetic field at high latitudes) (Keskinen and Ossakow, 1981, 1983). Later the theory of this basic gradient drift process was extended to include the effects of auroral currents at high latitudes on its quantitative thresholds and behaviour. These have been proposed to be the dominant plasma structuring mechanisms in the southward IMF polar cap ionosphere. Velocity shear driven plasma instabilities are now also known to occur for sufficiently severe velocity shears (Basu et al., 1988, 1990) and are believed to dominate the northward IMF polar cap. Keskinen et al. (1988) has applied a Kelvin-Helmholtz instability theory to these latter instabilities, adding the refinement of ionospheric-magnetospheric electrical coupling. Tsunoda (1988), in a broad review paper, has further suggested a "stirring" mechanism, that in effect leads to interchange of low density plasma fluxtubes with high density. Although not discussed there, we note that a theoretical examination of "stirring" would have to include gradients perpendicular to the magnetic field, of mobility or conductivity driven by particle precipitation, a term not yet included to our knowledge.

The HF radar measurements do not provide any direct means to distinguish between the different candidates of cusp plasma irregularity formation, but the combination of optics and CUTLASS may give us some insight though. The abrupt drop in backscatter power about 1020 UT on December 24 (see Fig. 6) corresponds to a near simultaneous drop in the line-of-sight away flows and narrowing Doppler spectral widths. This is attributed to the IMF $B_{Z}$ polarity change from weakly negative to weakly positive observed some $17 \mathrm{~min}$ earlier by WIND under $B_{Y}$ dominated conditions. The all-sky imagery confirms that the movements of auroral intensification were strictly westward without any sign of a poleward pull, the situation one would expect for the conditions of an extremely strong IMF $B_{Y}$ dominance $(\sim 15 \mathrm{nT})$. The sudden fall in backscatter power is taken to indicate that backscattering irregularities reduced forming. This would be consistent with the gradient drift instability process, which requires poleward plasma flow to be active near the cusp precipitation boundary (see Introduction).

The gradient drift instability and current convective instability both requires a density gradient on which to operate (Ossakow and Chaturvedi, 1979; Chaturvedi and Ossakow, 1981). Observations and modelling demonstrated by Waterman et al. (1994) and Millward et al. (1999) show that F-region density values of the order of 2 to $4 \times 10^{11} \mathrm{~m}^{-3}$ easily build up due to soft magnetosheath precipitation. Recent observation by Walker et al. $(1998,1999)$ show that cusp precipitation are associated by a well-defined sharp density gradient at the equatorward boundary. The overall good correlation between the radar cusp and optical cusp equatorward boundaries suggest an intimate relationship between increased electron density due particle impact ionisation and enhanced radar backscatter, as earlier proposed by Yeoman et al. (1997). It may well be that the electron precipitation itself is structured on decameter scale lengths. The observations here were acquired near winter solstice at solar minimum conditions. This demands further consideration of local (particle precipitation) production of plasma, versus transport from elsewhere (as in standard "polar cap patch" models, e.g. 
Sojka et al., 1994) in looking for the source of density gradients to feed irregularity formation processes here. Based on Sondrestromfjord ISR observations of plasma dynamics, combined with scintillation measurements of plasma irregularities, Basu et al. (1994) postulated that the gradient drift plasma instability mechanism generates irregularities associated with discrete plasma density enhancements in the cusp polar cap region, and that the shear-driven instability may generate irregularities in the intervening low-density regions. They calculated growth time for the gradient instability process operating in weakly collisional plasma at $400 \mathrm{~km}$ altitude to be of the order of $30 \mathrm{~s}$. This likely explains why the radar cusp boundary is offset north of the precipitation boundary by a few tens of kilometres.

The radar and optical auroral activities lines up very well at the equatorward boundary, but radar cusp backscatter extends far north of the optical aurora, in particular when IMF $B_{Z}$ has significant negative values associated with strong poleward flows. This follows directly from the decay rates and well-known long lifetimes for irregularities in the dark polar cap (e.g. Basu et al., 1998). Note also that the radar cusp activity does not accompany the east-west dynamics of the optical events very well. These observations taken together indicate that backscatter irregularities are more long-lived than the optical events and that the irregularities formed convect with the plasma (see also Yeoman et al., 1997).

\section{Summary and concluding remarks}

A detailed study on the correlation between radar and optical cusp auroral morphology has been accomplished in a $2 \mathrm{D}$ perspective. The study is based on two December days of red-dominated type 1 cusp auroral activity associated with strong radar backscatter seen by the CUTLASS Finland HF radar above Svalbard. The $\geq 220 \mathrm{~m} \mathrm{~s}^{-1}$ spectral width criterion proves to be a robust cusp identifier. The $\geq 220 \mathrm{~m} \mathrm{~s}^{-1}$ spectral width enhancement boundary lines up and correlates remarkably well with the type 1 cusp auroral boundary. A variety of boundary transitions was observed in the radar Doppler spectra, changing shape from narrow single-peak to broad multi-peak, narrow single-peak to broad artificial, or just a broadening of a single-peak spectrum. Largest discrepancies between the $\geq 220 \mathrm{~m} \mathrm{~s}^{-1}$ spectral width boundary and the optical cusp boundary are associated with the onset and fading of radar cusp aurora, but even in periods of strong backscatter, there is a one degree spread in collocation of the two boundaries. Our preliminary investigation indicates that a combination of spectral width and spectral shape may pin the radar cusp boundary more accurately. However, future work based on a larger data set will be necessary to firmly establish a refined set of criteria for identifying the cusp boundary by radar. The cusp is a very dynamic region, and the scattered picture of offsets between the radar and optical cusp boundaries are partly due to factors like variable plasma drift and growth-time for plasma instability to develop, plus uncertainties associated with positioning of radar gates and variability in the auroral emission altitude.

The onset time for radar cusp as seen by CUTLASS Finland above Svalbard near winter solstice at solar minimum conditions appears to be regulated by radio wave propagation conditions rather than lack of plasma irregularities. The abrupt fade in radar cusp backscatter on December 24, 1995 seems connected to an IMF $B_{z}$ polarity change, and was found consistent with switching the gradient drift instability from an unstable (on) to a stable geometry (off). However, other instability processes cannot be ruled out. The combination of EISCAT Svalbard radar, CUTLASS and optics will open interesting new possibilities to conduct more direct studies of the relationship between cusp precipitation, formation of density gradients, and HF backscatter.

What we can unequivocally state however is that studies of this type can and should define the degree to which HF coherent radar data can sense and track magnetospheric boundaries, in particular the cusp. We have identified how to significantly reduce the uncertainty of cusp boundary locations by optical techniques, especially for cases where the cusp boundary is south of the optical station. This advance follows from development here of new better approaches to processing the data. We have also identified better criteria for interpretation of the HF coherent radar data, by better distinguishing between the three mechanisms that can produce the HF coherent radar echoes, rather than continue acceptance of different assumptions made by different workers leading to different interpretations of data. This advance follows from merging here recent findings from two very different experimental techniques, to define better the physical processes at work. This improved physical framework, more clearly defined by the need to fit more observational constraints, should lead to stronger conclusions from HF radar data studies. In total, it is hoped that this work will speed the way to letting a broader community, use a larger base of data, with greater confidence, to better understand dayside aurora, cusp, and dynamic boundary processes in the solar wind driven magnetosphereionosphere system.

Acknowledgements. The authors thank D. Evans for the NOAA observations, and K. Oglivie and R. Lepping for the key parameter WIND data used in this study. CUTLASS is supported by the Particle Physics and Astronomy Research Council (PPARC), UK, the Swedish Institute for Space Physics, and the Finnish Meteorological Institute, Helsinki. Financial support has provided by Norwegian Research Council, UNIS grant 9/963 and AFOSR task 2310G9. This work was initiated during JM's sabbatical stay at Air Force Research Laboratory, VSB, Hanscom AFB.

Topical Editor Denis Alcaycle thanks A. S Rodger and A. D. $\mathrm{M}$ Walker for their help in evaluating this paper.

\section{References}

André, R., C. Hanuise, J.-P. Villain, and J.-C. Cerisier, HF radars: multifrequency study of refraction effects and localization of scattering, Radio Sci., 32, 153, 1997. 
André, R., M. Pinnock, and A. S. Rodger, On the SuperDARN autocorrelation function observed in the ionospheric cusp, Geophys. Res. Lett., 26, 3353, 1999.

Baker, K. B., R. A. Greenwald, J. M. Ruohoniemi, J. R. Dudeney, M. Pinnock, P. T. Newell, M. E. Greenspan, and C.-I. Meng, Simultaneous HF-radar and MSP observations of the cusp, Geophys. Res. Lett., 17, 1869, 1990.

Baker, K., J. Dudeney, R. Greenwald, M. Pinnock, P. Newell, A. Rodger, N. Mattin, and C.-I. Meng, HF radar signatures of the cusp and low-latitude boundary layer, J. Geophys. Res., 100, 7671, 1995.

Basinska, E. M., W. J. Burke, N. C. Maynard, W. J. Hughes, J. D. Winningham, and W. B. Hanson, Small-scale electrodynamics of the cusp with northward interplanetary magnetic field, J. Geophys. Res., 97, 6369, 1992.

Basu, Su., S. Basu, E. MacKenzie, P. F. Fougere, W. R. Coley, N. C. Maynard, J. D. Winningham, M. Sugiura, W. B. Hanson, and W. R. Hoegy, Simultaneous density and electric field fluctuation spectra associated with velocity shears in the auroral oval, J. Geophys. Res., 93, 115, 1988.

Basu, Su., S. Basu, E. MacKenzie, W. R. Coley, J. R. Sharber, and W. R. Hoegy, Plasma structuring by the gradient drift instability at high latitudes and comparison with velocity shear driven processes, J. Geophys. Res., 95, 7799, 1990.

Basu, S., Su. Basu, P. K. Chaturvedi, C. M. Bryant, Jr., Irregularity structures in the cusp/cleft and polar cap regions, Radio Sci., 29, 195, 1994

Basu, S., E. J. Weber, T. W. Bullett, M. J. Keskinen, E. MacKenzie, P. Doherty, R. Sheehan, H. Kuenzler, P. Ning, and J. Bongiolatti, Characteristics of plasma structuring in the cusp/cleft region at Svalbard, Radio Sci., 33, 1885, 1998.

Chaturvedi, P. K., and S. L. Ossakow, The current convective instability as applied to the auroral ionosphere, J. Geophys. Res., 86, 4811, 1981.

Davies, J. A., M. Lester, S. E. Milan, and T. K. Yeoman, A comparison of velocity measurements from the CUTLASS Finland radar and the EISCAT UHF system, Ann. Geophysicae, 17, 892-902, 1999.

Dyrud, L. P., M. J. Engebretson, J. L. Posh, W. J. Hugues, H. Fukunishi, R. L. Arnoldy, P. T. Newell, and R. B. Horne, Ground observations and possible source regions of two types of Pc1-2 micropulsations at very high-latitudes, J. Geophys. Res., 102, 27 011, 1997.

Erlandson, R. E., and B. J. Anderson, Pc1 waves in the ionosphere: a statistical study, J. Geophys. Res., 101, 7843-7857, 1996.

Greenwald, R. A., K. B. Baker, J. R. Dudeney, M. Pinnock, T. B. Jones, E. C. Thomas, J.-P. Villain, J.-C. Cerisier, C. Senior, C. Hanuise, R. D. Hunsucker, G. Sofko, J. Koehler, E. Nilsen, R. Pellinen, A. D. M. Walker, N. Sato, and H. Yamagishi, DARN/SuperDARN: a global view of the dynamics of highlatitude ionospheric convection, Space Sci. Rev., 71, 761, 1995.

Hanuise, C., J. P. Villain, D. Gresillon, G. Cabrit, R. A. Greenwald, and K. B. Baker, Interpretation of HF radar ionospheric Doppler Spectra collective wave scattering theory, Ann. Geophysicae, 11, 29, 1993.

Keskinen, M. J., and S. L. Ossakow, On the spatial power spectrum of the $\mathbf{E} \times \mathbf{B}$ gradient drift instability in ionospheric plasma clouds, J. Geophys. Res., 86, 6987, 1981.

Keskinen, M. J., and S. L. Ossakow, Theories of high latitude ionospheric irregularities: a review, Radio Sci., 18, 1077, 1983.

Keskinen, M. J., H. G. Mitchell, J. A. Fedder, P. Satyanarayana, S. T. Zelesak, and J. D. Huba, Nonlinear evolution of the Kelvin-Helmholtz instability in the high-latitude ionosphere, $J$. Geophys. Res., 93, 137, 1988.

Lepping, R. P., M. H. Acuna, L. F. Burlaga, W. M. Farrell, J. A. Slavin, K. H. Schatten, F. Mariani, N. F. Ness, F. M. Neubauer, Y. C. Whang, J. B. Byrnes, R. S. Kennon, P. V. Panetta, J. Scheifele, and E. M. Worley, The Wind magnetic field investigation, Space Sci. Rev., 71, 207, 1995.
Lockwood, M., and J. Moen, Ion populations on open field lines within the low-latitude boundary layer: theory and observations during a dayside transient event, Geophys. Res. Lett., 23, 2895, 1996.

Lockwood, M., P. E. Sandholt, S. W. H. Cowley, and T. Oguti, Interplanetary magnetic field control of dayside auroral activity and the transfer of momentum across the dayside magnetopause, Planet. Space Sci., 37, 1347, 1989.

Lockwood, M., S. Fuselier, A. D. M. Walker, and F. Søraas, A summary of the NATO ASI on polar cap boundary phenomena, in Polar cap boundary phenomena Eds. J. Moen, A. Egeland, and M. Lockwood, NATO Advanced Study Institute Series, Kluwer Academic Press, Dordredt, vol. 509, p. 415,1998

Maynard, N. C., T. L. Aggson, E. M. Basinska, W. J. Burke, P. Craven, W. K. Peterson, M. Sugiura, and D. R. Weimer, Magnetospheric boundary dynamics: DE-1 and DE-2 observations near the magnetopause and cusp, J. Geophys. Res., 96, 3505, 1991.

Milan, S. E., T. K. Yeoman, M. Lester, E. C. Thomas, and T. B. Jones, Initial backscatter occurrence statistics from the CUTLASS HF radars, Ann. Geophysicae, 15, 703, 1997.

Milan, S. E., T. K. Yeoman, and M. Lester, The dayside auroral zone as a hard target for coherent HF radars, Geophys. Res. Lett., 25, 3717, 1998.

Milan, S. E., M. Lester, S. W. H. Cowley, J. Moen, P. E. Sandholt, and C. J. Owen, Meridian-scanning photometer, coherent HF radar, and magnetometer observations of the cusp: a case study, Ann. Geophysicae, 17, 159, 1999.

Millward, G. H., R. J. Moffett, H. F. Balmforth, and A. S. Rodger, Modeling of ionospheric effects of ion and electron precipitation in the cusp, J. Geophys. Res., 104, 24 603, 1999.

Moen, J., D. Evans, H. C. Carlson, and M. Lockwood, Dayside moving auroral transients related to LLBL dynamics, Geophys. Res. Lett., 23, 3247, 1996.

Moen, J., D. A. Lorentzen, and F. Sigernes, Dayside moving auroral forms and bursty proton auroral events in relation to particle boundaries observed by NOAA-12, J. Geophys. Res., 103, $14855,1998$.

Moen, J., H. C. Carlson, and P. E. Sandholt, Continuous observation of cusp auroral dynamics in response to an IMF $B_{Y}$ polarity change, Geophys. Res. Lett., 26, 1243, 1999.

Newell, P. T., and C.-I. Meng, The cusp and the cleft/boundary layer: low-altitude identification and statistical local time variation, J. Geophys. Res., 93, 14 549, 1988.

Ogilvie, K. W., D. J. Chornay, R. J. Fritzenreiter, F. Hunsaker, J. Keller, J. Lobell, G. Miller, J. D. Scudder, E. C. Sittler Jr., R. B. Torbert, D. Bodet, G. Needell, A. J. Lazarus, J. T. Steinberg, J. H. Tappan, A. Mavretic, and E. Gergin, SWE, a comprehensive plasma instrument for the Wind spacecraft, Space Sci. Rev., 71, 55, 1995.

Ossakow, S. L., and P. K. Chaturverdi, Current convective instability in the diffuse aurora, Geophys. Res. Lett., 6, 332, 1979.

Pilkington, G. R., J. W. Munch, H. J. Braun, and H. G. Möller, Comparison of ground HF backscatter and simultaneous particle and plasmapause measurements from a polar orbiting satellite, J. Atmos. Terr. Phys., 37, 337, 1975.

Rodger, A. S., S. B. Mende, T. J. Rosenberg, and K. B. Baker, Simultaneous optical and HF radar observations of the ionospheric cusp, Geophys. Res. Lett., 22, 2045, 1995.

Ruohoniemi, J. M., R. A. Greenwald, K. B. Baker, and J. P. Villain, Drift motions of small-scale irregularities in the high-latitude $\mathbf{F}$ region: an experimental comparison with plasma drift motions, J. Geophys. Res., 92, 4553, 1987.

Sandholt, P. E., J. Moen, A. Rudland, D. Opsvik, W. F. Denig, and T. Hansen, Auroral event sequences at the dayside polar cap boundary for positive and negative IMF $B_{Y}, J$. Geophys. Res., 98, 7737, 1993.

Sandholt, P. E., C. J. Farrugia, J. Moen, Ø. Noraberg, B. Lybekk, T. Sten, and T. L. Hansen, A classification of dayside auroral 
forms and activities as a function of IMF orientation, J. Geophys. Res., 103, 23 325, 1998.

Sojka, J. J., M. D. Bowline, R. W. Schunck, D. T. Decker, C. E. Valladares, R. Sheehan, D. N. Anderson, and R. A. Heelis, Modeling polar cap $F$ region patches using time varying convection, Geophys. Res. Lett., 20, 1783, 1993.

Tsunuda, R. T., High-latitude F-region irregularities: a review and synthesis, Rev. Geophys., 26, 719, 1988.

Villain, J. P., G. Caudal, and C. Hanuise, A SAFARI-EISCAT comparison between the velocity of $\mathrm{F}$ region small-scale irregularities and the ion drift, J. Geophys. Res., 90, 8433, 1985.

Walker, I. K., J. Moen, C. N. Mitchell, L. Kersley, and P. E. Sandholt, Magnetopause reconnection observed using ionospheric tomography, Geophys. Res. Lett., 25, 293, 1998.
Walker, I. K., J. Moen, L. Kersley, and D. A. Lorentzen, On the possible role of cusp/cleft precipitation of polar-cap patches, Ann. Geophysicae, in press, 1999.

Waterman, J., D. Lummerzheim, O. de la Beaujardiere, P. T. Newell, and F. J. Rich, Ionospheric footprint of magnetosheathlike particle precipitation observed by an incoherent scatter radar, J. Geophys. Res., 99, 3855, 1994.

Wright, D. M., and T. K. Yeoman, High resolution bistatic HF radar observations of ULF waves in artificially generated backscatter, Geophys. Res. Lett., 26, 2825, 1999.

Yeoman, T. K., M. Lester, S. W. H. Cowley, S. E. Milan, J. Moen and P. E. Sandholt, Simultaneous observations of the cusp in optical, DMSP and HF radar data, Geophys. Res. Lett., 24, 2251, 1997. 